\title{
LA-6025-MS
}

Informal Report

UC-34a

Reporting Date: July 1975

Issued: August 1975

\section{Statistical Thermodynamic Properties of Hexafluoride Molecules}

by

Douglas Jackson

scientific laboratory

of the University of Califernia

LOS ALAMOS, NEW MEXICO 87545

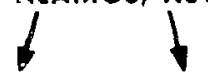

An Affirmotive Action / Equal Opportunity Employer

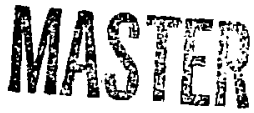


In the interest of prompt distribution, this report was not edited by the Technical Information staff.

Printed in the United Stotes of Amarica. Avrilable trum

National Technical Information Service

U S Department of Commerce

5285 Port Ropal Road

Springtisld, VA 22151

Price: Prinled Copy 24.00 Microfiche $\$ 2.25$

This report wav prepared ss en cccount of work sponoted

bv the Uniled States Goversocont. Neither the United Blatos

nor the United Stales Eortey Rreencelh and Development Ad.

truters. Iubcontrectora. of their employes. matiet any

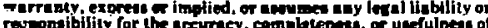

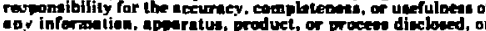

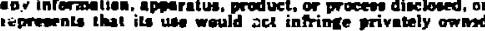

rizhix. 
STATIST ILAL THERMOIYMAMIC PROPLRTIES OF HEXAHUORTDE MOLECULES

[koug las Jackson

\begin{abstract}
Useful statistical thermodynamic properties of fiftect octahedral hexafluorides are presented in graphical form. These include: vilrational partition function; populations of '...-1ying vibrational states; densitias of vibrational states; and cumulative vibrational population distributions. Vilues an be read directly from the graphs with an accuracy consistent with the accurac" of the experimental deterininations of the vibrational fundamental frequencies, and the approximate validity of the harmonic oscillator approximation.
\end{abstract}

\section{INTROLUCTION}

The purpose of this report is to present in the form of curves, and certain analytic expressions, some statistical thermodynanic properties of 15 hexafluoride molecules. Some of this data has been independently generated and used previously,e.g., Ref. l. We feel that this reasonably comprehensive set of data will be useful as a reference and may climinate some duplication of effort.

a!l of these curves are computer-generated using only the 15 fundamental vibrational frequencies.

The frequencies used were taken from lief, 2 and are presented in Table I for each of the nolecules considered.

For each set of curves the corresponding section of this report details the manner in which they werc gencrated. In the last section a few words are silid about accuracy.

\section{T. ROPULATION OF LUW ENERG广 VIBRATIONAL STATES}

Each of the hexafluorides has $: 5$ funcamental modes of vibration. However, since they have a twofold and four three-fold degeneracies, it is suffi.cient to consider the six distinct frequencies $\omega_{1}$, $\ldots, w_{6}$. Thus if $w_{1}^{\prime}, \ldots, w_{15}^{\prime}$ are the 15 fundamental frequencies we have

$$
\omega_{1}=\omega_{1}^{\prime}
$$

$$
w_{2}=\omega_{2}^{\prime}=\omega_{3}^{\prime}
$$

ard

$$
\omega_{i}=\omega_{j i-5}^{\prime}=\omega_{5 i-4}^{\prime}=\omega_{j i-j}^{\prime},
$$

for $i=3,4,5,6$.

Lihewise if $y_{1}, \ldots . V_{i s}$ are the viorational 'uinta in each of the $1 \overline{5}$ fundamental modes we use only the legenerate vibrational quanta $v_{1}, \ldots v_{0}$ wicre

$$
\begin{gathered}
v_{1}=v_{1}^{\prime} \\
v_{2}=v_{2}^{\prime}+v_{5}^{\prime}
\end{gathered}
$$

and

$$
v_{i}=v_{5 i-5}^{\prime}+v_{5 i-4}^{\prime}+v_{5 i-3}^{\prime}
$$

for $i=5,4,5,6$.

$$
\text { lence, for each vibrational state } v_{1} \ldots, v_{6}
$$

the degeneracy factor

$$
\mathrm{D}=\left(V_{2}+1\right) \prod_{i=3}^{0} \frac{\left(V_{i}+1\right)\left(V_{i}+2\right)}{2}
$$

$y$ iclds the number of vibrational states which have the degenerate vibrational state $v_{1}, \ldots, v_{6}$, tor convenience we will refer to the degenerate 
:ibrational state as the vibrational state or some. times merely as the state of a molecule.

Now for a fixed vibrational state $v_{1}, \ldots, v_{6}$ let $F(T)$ be the saltion of molecules, at temperature $T$, which are in that state. Then $F(T)$ is given by

$$
F(T)=D \frac{e^{-\frac{\Sigma \omega_{i} v_{i}}{k T}}}{2(T)} .
$$

where $Z(T)$ is the partition function, as detined in the next section, and $k$ is the Boltzmann constant.

In Figs. I througn $15 \mathrm{~F}(\mathrm{~T})$ is plotted for 10 , 11, or 12 highly populsced vibrational states for with of the hexafluor:des considered.

Notice that the reduced vibrational states do not always represerg the most populated states. For example, the stats $(0,0,0,0,0,3)$ is never plotted but, for a few nolecules, is more highly populated than the states which are plotted.

11I. THE PARTITION FUNCTION, Z(T)

Let $d_{1}, \ldots, d_{1}, \ldots$ the degeneracy factors for the hexafluorides. Thus, we sec from the previous section that

$$
\begin{aligned}
& d_{1}=1 \\
& d_{2}=?
\end{aligned}
$$

2. 1

$$
d_{i}=j
$$

for $i=3,4,5,6$.

Vow the definition of the partition function is given by

$$
\Sigma(T)=\sum D e^{-\frac{E}{k T}}
$$

where the sum is taken over all vibrational states $\left(v_{1}, \ldots, v_{6}\right)$ and for each state $D$ is the degeneracy and $\mathrm{t}$ is the vibrational energy defined as

$$
F=\sum_{i=1}^{6} w_{i} v_{i}
$$

The reader is referred to the previous section for the definition of 13 and "vibrational state."

Pinysically the function $Z(T)$ is proportional to the number of molecules per unit volume in a population of molecules having temperature $T$.
It is well known that the sum which defines $Z$ ('T) can be carried out analytically to yield

$$
z(l)=\prod_{i=1}^{6}\left(1-e^{-\frac{\omega_{i}}{k T}}\right)^{-d_{i}} .
$$

This expression was used to calculate $z(T)$ and the resulting curves are presented in Figs. 16 through 19 for cach of the 15 hexufluorides and for $0 \leq \mathrm{T} \leq$ $350^{\circ} K$. For convenience $z(T)$ is plotted for two temperature scales.

\section{JENSITY OF VIBRATIONAL STATLS}

A number of at tempts have been made at finding simple approximations to the number of vibrational :tates with energy in a given energy range. The mathematical approach has been to try and find general formulas which depend only on the $w_{i}$, c.g., kef. 3 . Physical scientist have tended to include in their approximations one or more parameters, besides the $\omega_{i}$, which are determined hy best fit to actual data for each molecule, e.g., kef. 4 .

The second approach requires more conputation and yields better results, especially when the energy range of interest is limited. We have chosen the second approach but have used a different functional form than those appearing in the literature. A computer-generated count of the states was made and the fit is to this data for $0 \leq E \leq 5000 \mathrm{~cm}^{-1}$ for each of the hexafluoride molecules in Table $I$. The functiona) form used is not asymptotically correct as $E$ gocs to infinite and hence should not be used for energies greater than 5000 wavenumbers $\left(\mathrm{cm}^{-1}\right)$. However, for these molecules and for temperatures of no more than $400 K$ only a small fraction of the population has energy greater than $5000 \mathrm{~cm}^{-1}$. Define $N(E)$ by

$$
N(E)=\left\{\begin{array}{c}
\sum 0 \\
\left\{\left(V_{i}\right): 0 \leq w_{1} v_{1}+\ldots+w_{6} v_{6} \leq E\right\}
\end{array}\right.
$$

where, as indicated, the sum is over all vibrational states of energy not greater than $E$, and $D$ is the degeneracy of each state as defined in Section II. For $0 \leq \mathrm{E} \leq 5000=\mathrm{m}^{-1}$ ye used a least-squares cubic fit to the curve $\ln N(E)$ vs $\ln \mathrm{F}$. Thus we have

$$
\ln N(E)=P_{3}(\ln E)
$$


where

$$
P_{3}(x)=b_{1} x^{3}+b_{2} x^{2}+b_{3} x+b_{4}
$$

The cocfficients of $\mathrm{P}_{3}$, which were found for each molecule are presented in Table 11 .

Now the derivative of $N(E)$ is, of course, either. zero or undefined for each value of $E$ beciase $N(E)$ is a step function. However, we write $N^{\prime}(E)$ to mean the averago number of states per $\mathrm{cm}^{-1}$ in a small interval (say $100 \mathrm{~cm}^{-1}$ ) centered at $\mathrm{E}$. Hence, for the density of vibrational states $g(E)=y^{\prime}(E)$ we use

$$
g(E)=\left(\frac{P_{3}^{\prime}(\ln E)}{E}\right) e^{P_{3}(\ln E)}
$$

where $P_{3}^{\prime}$ is the derivative of the polynomial $P_{3}$.

We use this equation to compute $g(E)$ and the results are presented in Figs. 20 through 25 . For convenience $g(E)$ is plotted for two energy scales.

\section{v. CUMULATIVE POPULATION DISTHIBUTION}

For a population of molecules at temperature $T$ let $G(E, T)$ be the fraction of the molecules which have energy less than or equal to $\mathrm{t}:$. Then if $g(E)$ is the density of states function we have

$$
G(E, T)=\int_{0}^{E} g(y) e^{-\frac{y}{k T}} d y .
$$

$\mathrm{G}(E, T)$ was calculated a.ing this equation where the function $g$ is defined in terms of a cubic polynomial as discussed in the previous section.

For each of the nexaflurides we plot $G(E, T)$ as a function of $\mathrm{E}$. for values of $\mathrm{T}$ flom $200 \mathrm{~K}$ to $400 \mathrm{~K}$ in increments of $20 \mathrm{~K}$. Th: results are presented in Figs. 26 through $3 \overline{3}$, where the top curve in each figure represents the distribution for $T=200 \mathrm{~K}$ the next for $T=220 \mathrm{~K}$ and the bsttom for $T=400 \mathrm{~K}$.
I'I. ACCURACY

The main sources of inaccuracy in these curves are due to three factors. The first source of error is the value used for the fundamental frequencies. The second is the model, which considers only vibrational states. Also we use only first order terms in the vibrational quantum numbers to define energy. The third is the quality of the analytic fit to the vibrational states distribution in energy.

No systematic study of quality of the analytic fit was made. We merely chose a sample of data points and compared the plotted data to the data from actual counting of states.

The density of states curves for $E \geq 1600 \mathrm{~cm}^{-1}$ are rarely off by $S \%$ or more. For $S F_{6}$ the fit is not this good un less we restrict to $E \geq 20 ! \% \mathrm{~cm}^{-1}$ and for most less stiff molecules it is sufficient to require $E \geq 1000 \mathrm{~cm}^{-1}$. The fit is poor for $E$ : $1000 \mathrm{~cm}^{-1}$ in almost all cases.

For the cumulative population distribution curves errors of $5^{\circ}$ or more are very rare while errors of $3^{\circ}$ are common over the entire range plotted.

\section{REFERENCES}

2. Andrew V. Nowak and John L. Lyman, "The Temperature-Dependent Absorption Spectrum of the $v_{3}$ Band of $\mathrm{SF}_{6}$ at $10.6 \mathrm{\mu m}, " \mathrm{~J}$. Quant. Spectrosc. Radiat. Transfer, to be published.

2. H. H. Claasen, G. L. Goodman, J. H. llolloway, and $H$. Selig, "Raman Spectra of $\operatorname{MoF}_{6}, \mathrm{TcF}_{6}, \operatorname{ReF}_{6}$ $\mathrm{UF}_{6}, \mathrm{SF}_{6}, \mathrm{SeF}_{6}$, and $\mathrm{TeF}_{6}$ in the Vapor State," $J$. Chem. Phys. 5.3(1), (1970).

3. Thomas Lambe, "Bounds on the Number of Feasible Solutions to a Knapsack Problen," Siam J. Appl. Math. 26(2), (Mar. 1974).

4. P. J. Robinson and K. A. Holbrook, Unimolecular Reactions (Wiley Interscience, London, 1972), p. 131 . 


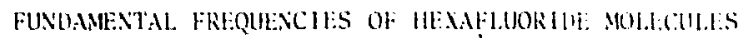
IN THE lidok $\left(\mathrm{cm}^{-1}\right)$

(uata from lief. 2)

\begin{tabular}{|c|c|c|c|c|c|c|}
\hline Molecule & -2 & $-\underline{v_{2}}$ & 3 & $\because$ & $\because 5$ & $" n$ \\
\hline$S F_{6}$ & 7.3 .5 & $6+1 .^{-}$ & 959.9 & 011.0 & 525.0 & $.31-.11$ \\
\hline Sef: & 706.9 & 658.7 & 780.0 & $45^{\circ} .11$ & 405.11 & $\therefore 6.1,11$ \\
\hline $\operatorname{TeF}_{G}$ & 697.1 & $(n ; 0) .3$ & -52.0 & $.325,11$ & 514.10 & $1 ! \cdots, 11$ \\
\hline $\mathrm{HOF}_{\mathrm{b}}$ & $7+1.5$ & 651.6 & -111.1 & 204.0 & ה1心." & 110.11 \\
\hline $\mathrm{Tel}_{6}$ & 712.9 & 639.0 & 748.0 & 265.11 & 297.19 & 1.45 .11 \\
\hline $\operatorname{RuF}_{6}$ & 675.0 & 624.0 & 735.0 & 275.11 & 28.5 .11 & 180.0 \\
\hline $\mathrm{RhF}_{6}$ & 634.0 & 595.0 & 224.0 & 28.3 .0 & 269.01 & 192.13 \\
\hline$W F_{6}$ & 771.0 & 677.2 & 711.0 & 258.0 & 520.0 & 127.0 \\
\hline $\operatorname{ReF}_{6}$ & 753.7 & 671.0 & 715.0 & $25-.0$ & 295.0 & 1.7 .01 \\
\hline $\mathrm{OsF}_{6}$ & 730.7 & 688.1 & 720.0 & 268.0 & 290.0 & 205.11 \\
\hline $\operatorname{IrF}_{h}$ & 701.7 & 145.0 & 719.0 & 270.11 & $26^{-} .0$ & 206.0 \\
\hline PtF 6 & 656.4 & 601.0 & 705.0 & $\therefore ? .10$ & 212.0 & 211.11 \\
\hline $\mathrm{UF}_{6}$ & 667.1 & 5.32 .5 & 624.0 & 186.2 & 202.0 & 112.0 \\
\hline $\operatorname{spF}_{6}$ & 654.0 & 5.35 .0 & 624.0 & 198.6 & 208.0 & 164.11 \\
\hline $\mathrm{PuF}_{6}$ & 628.0 & 523.0 & 016.0 & 206.0 & 211.0 & 173.0 \\
\hline
\end{tabular}




\section{IAแI II}

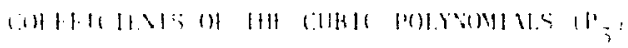
livil. I'; $101:$

$$
\begin{gathered}
P_{3}(x)=b_{1} x^{5} \cdot b_{2}+b_{3}+n_{1} \\
\text { i:lom }
\end{gathered}
$$

\begin{tabular}{|c|c|c|c|c|}
\hline Mn!esule & 11 & $b=$ & $\therefore$ & 1 \\
\hline$\therefore t$ & $0.1 .31,8$ & .1 .970 & ז & $-1^{-} .2111$ \\
\hline$\therefore D_{11}$ & 11.116161 & $-1.6,46 !)$ & $-x+1,1]$ & $1.7 .41 .=$ \\
\hline$|x \cdot|_{n}$ & $11.12 \therefore$ & $-1.8+194$ & $5.71 . ;$ & -4 - \\
\hline Ioti" & 11.11211 & $-1 .(1925$ & 1.1131 & $=1.160, t$ \\
\hline$\Leftrightarrow 1$ & 11.1211 & -1.38 is & $\therefore i s 0^{-}$ & .10 .2195 \\
\hline lini & י & -1.513 & (1. . & $1 \therefore \cdots$ \\
\hline Rht & 11.12421 & -1.12116 & 1.1515 & $-11.95-$ \\
\hline Wi & 11.121111 & -1.255 & 5.2501 .4 & $-8.968^{-}$ \\
\hline $\mathrm{BLF}$, & $11.1211^{-}$ & -1.3 .35 & $5 .^{--11}$ & $-110.20^{\circ}$ \\
\hline ns: & 0.151 .30 & - 1. & -150 & דi. \\
\hline $\ln$ & 1.15322 & $-1.3611^{-}$ & $\therefore 16.15$ & 1. \\
\hline Pit & $11.126=1$ & $-1.356-$ & $\therefore-7 ! 4$ & -10.111 \\
\hline $111:$ & $11.12 \therefore 5 \%$ & $-1 \ldots 1-13$ & t. . $2 S 1 \mathrm{x}$ & $-12 \therefore \therefore:$ \\
\hline$x_{4}$ & 11.1180 .1 & $-1.4 n]:$ & $1.21+t$ & -1120 \\
\hline $\mathrm{Pul}$ & $1.11 K 1:$ & $-1.11 \cdot 13 !$ & 1.12121 & $+\quad \therefore \quad 18,8\}$ \\
\hline
\end{tabular}




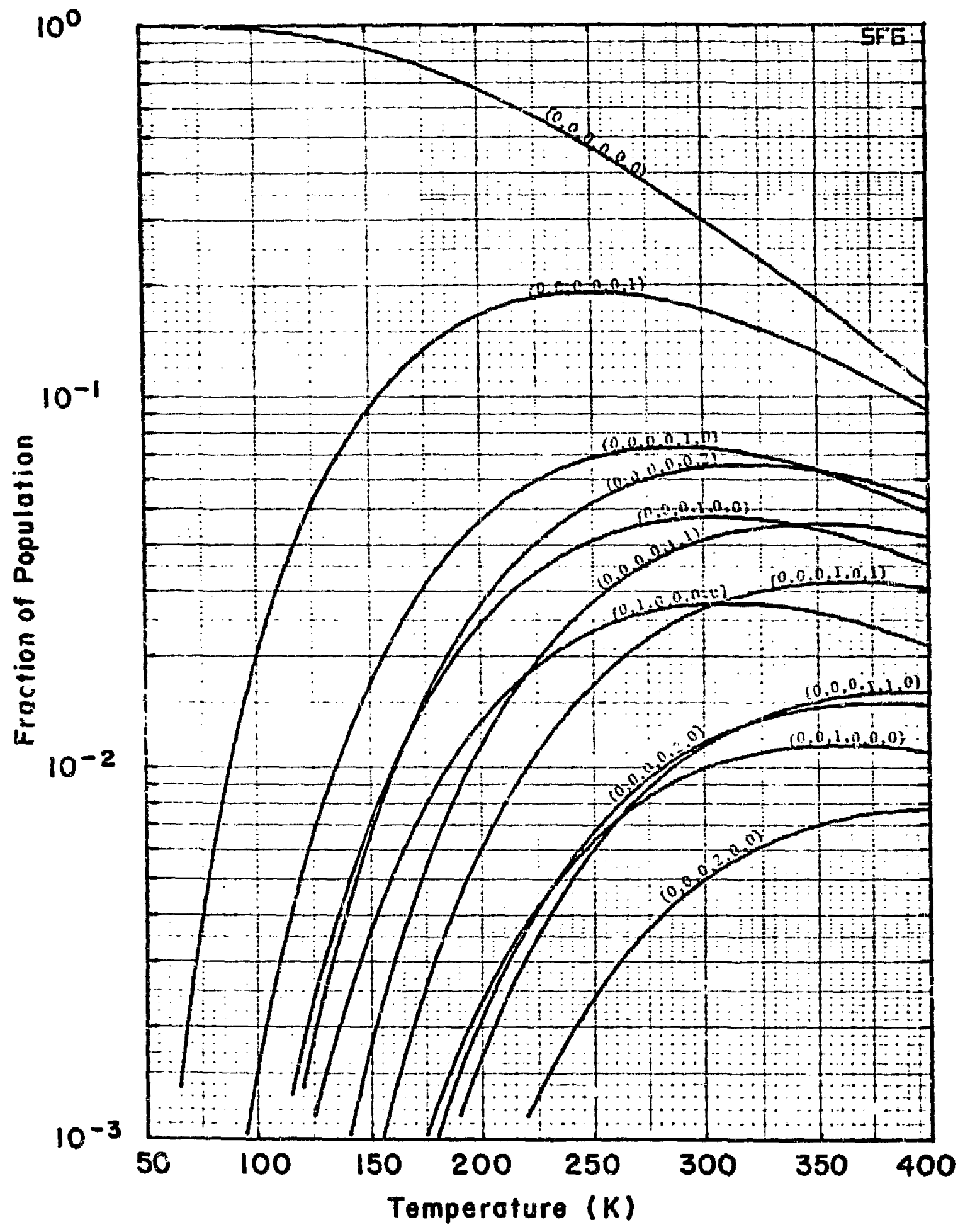

Fig. I Population of low-energy vibrational states of SF 6 


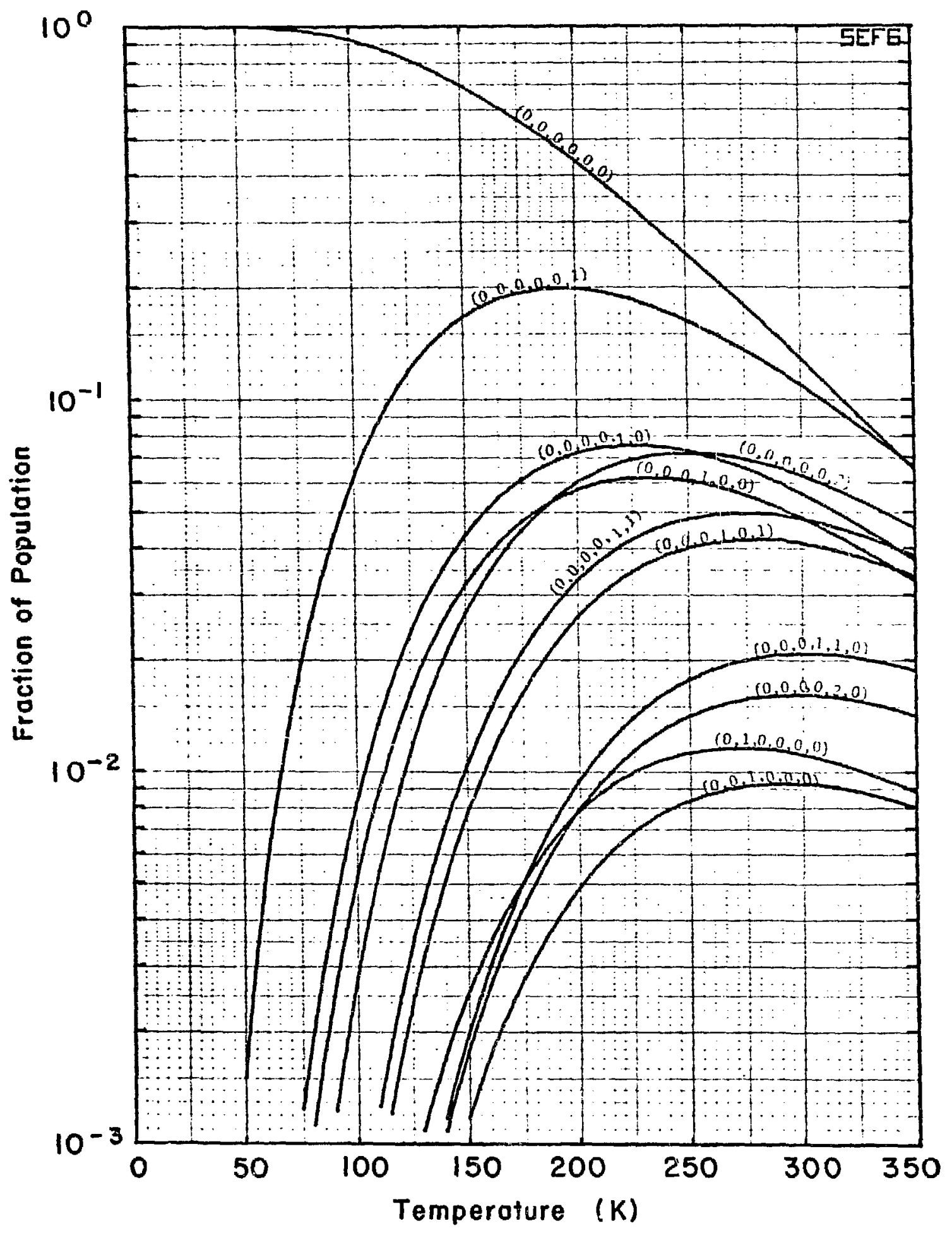

Fig. 2 Population of low-energy vibrational states of $\mathrm{SeF}_{6}$ 


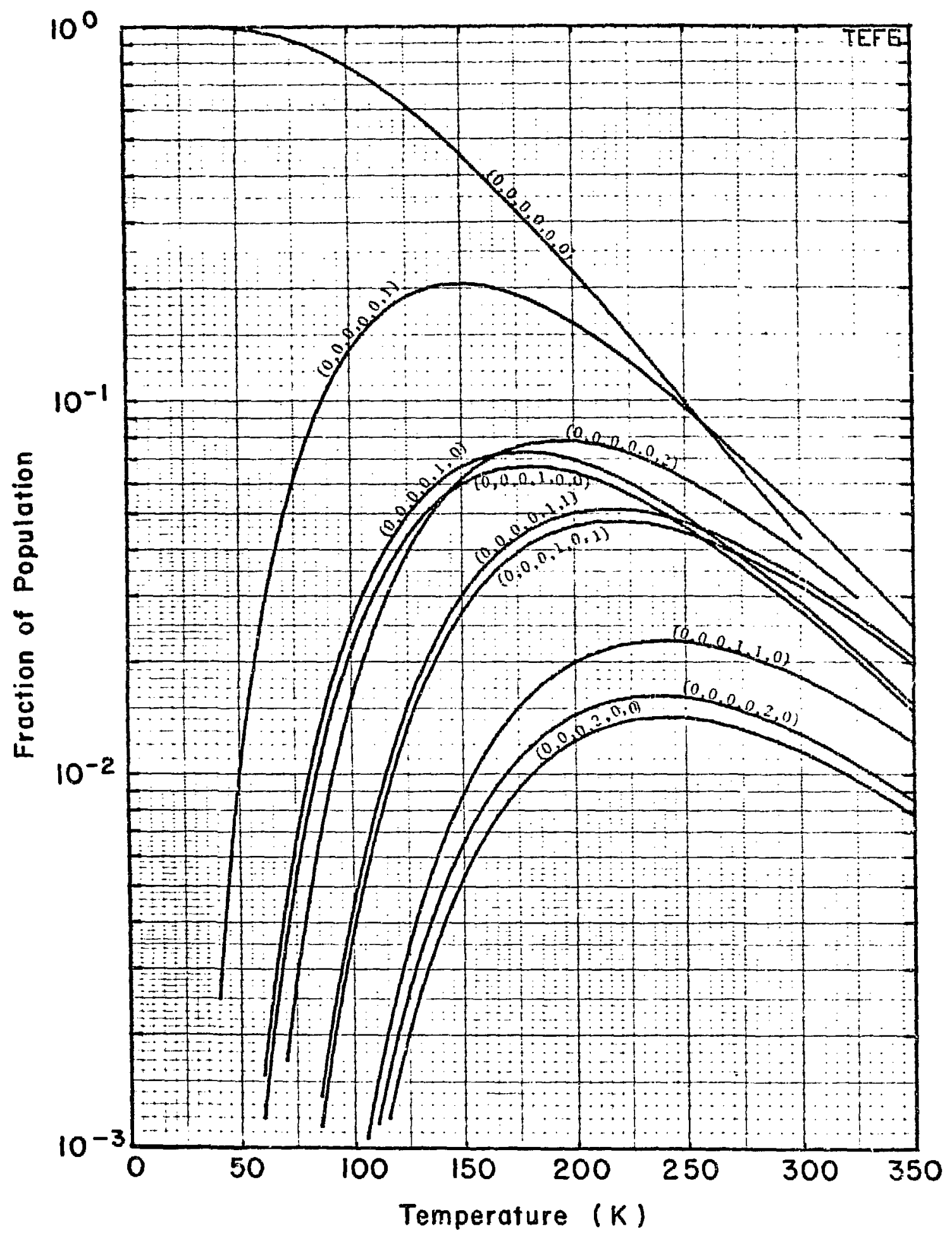

Fig. 3 Population of low-energy vibrational states of $\mathrm{TeF}_{6}$ 


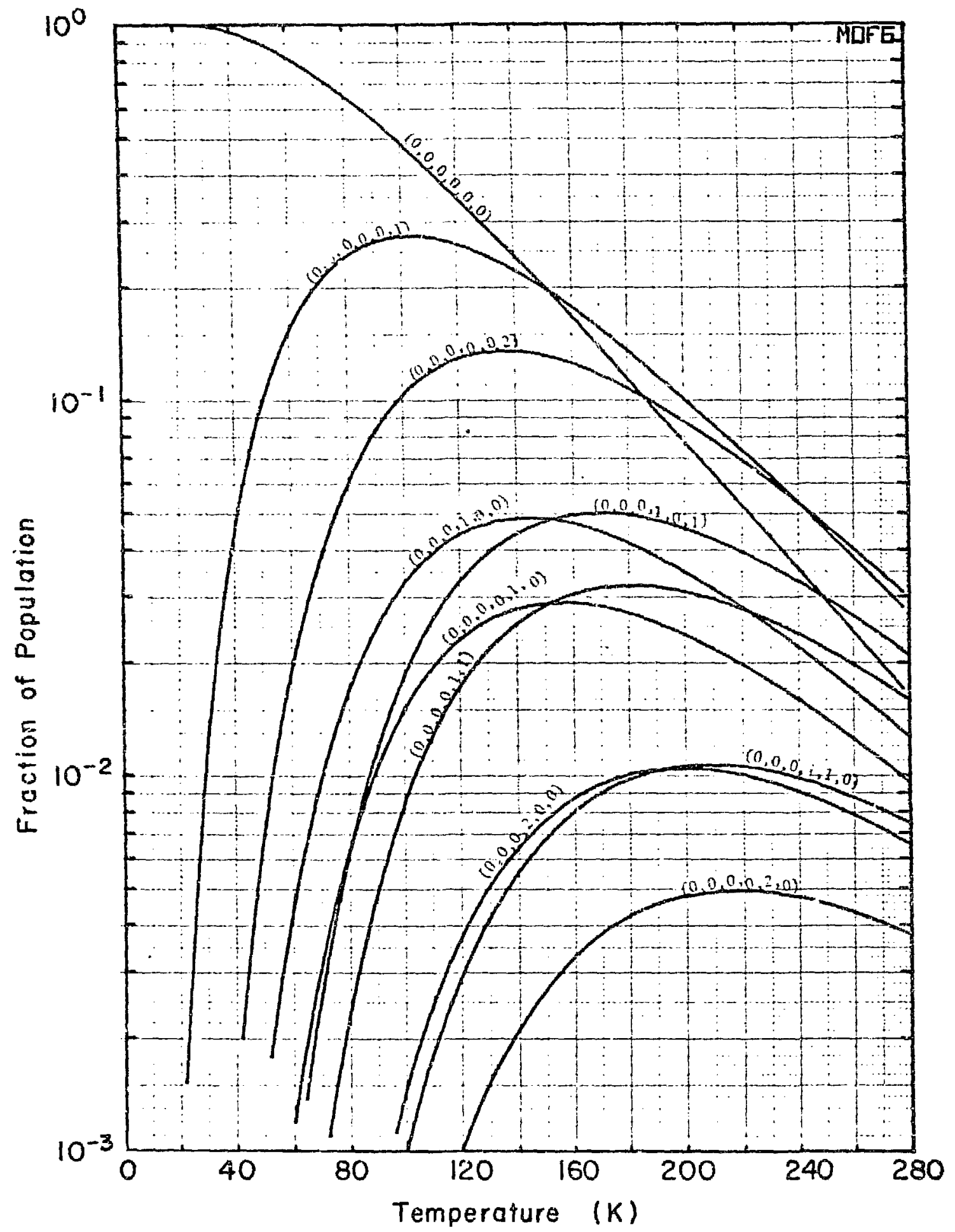

Fig. 4 Population of low-energy vibrational states of $\mathrm{MoF}_{6}$ 


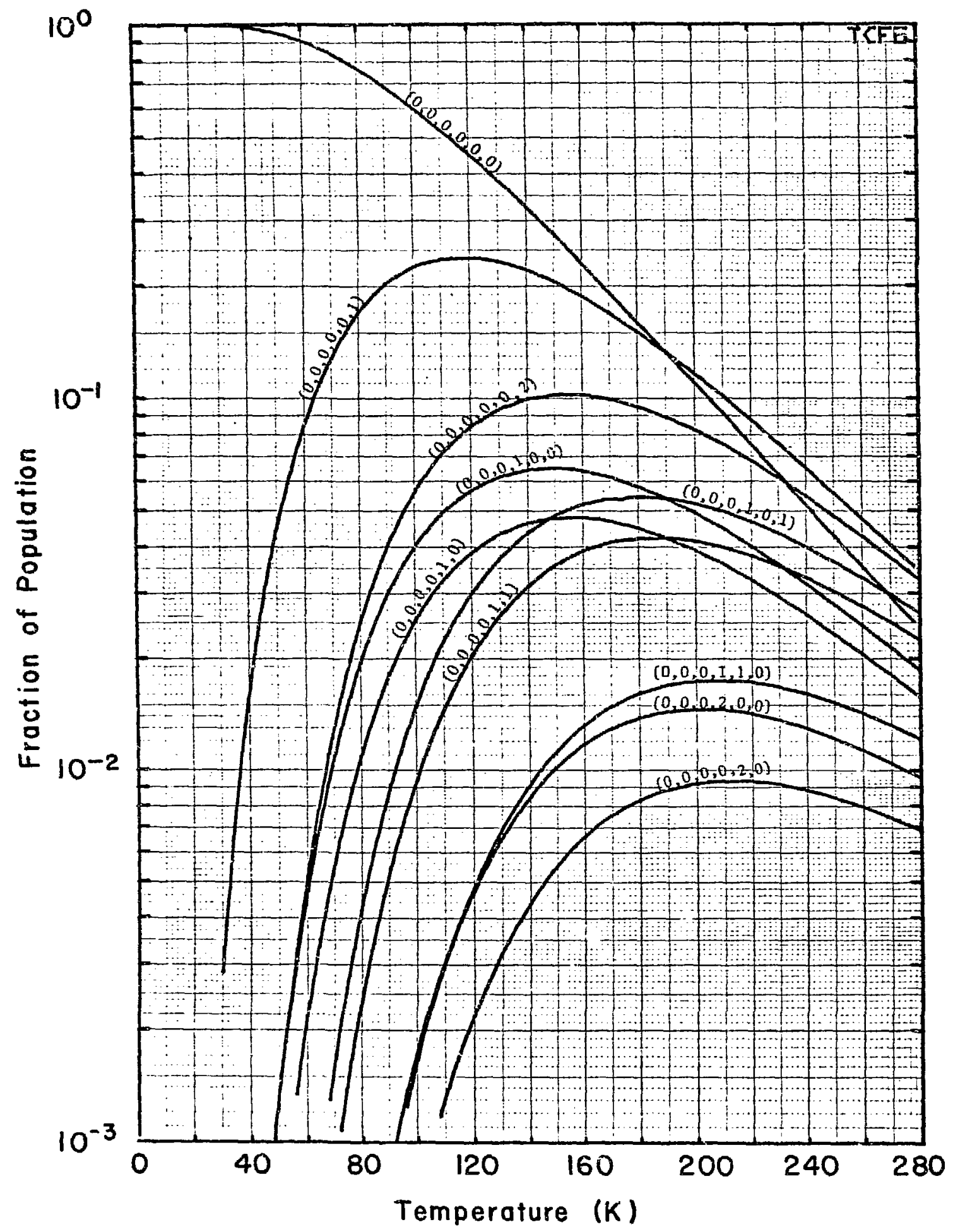

Fig. 5 Population of low-energy vibrational states of $\mathrm{TCF}_{6}$ 


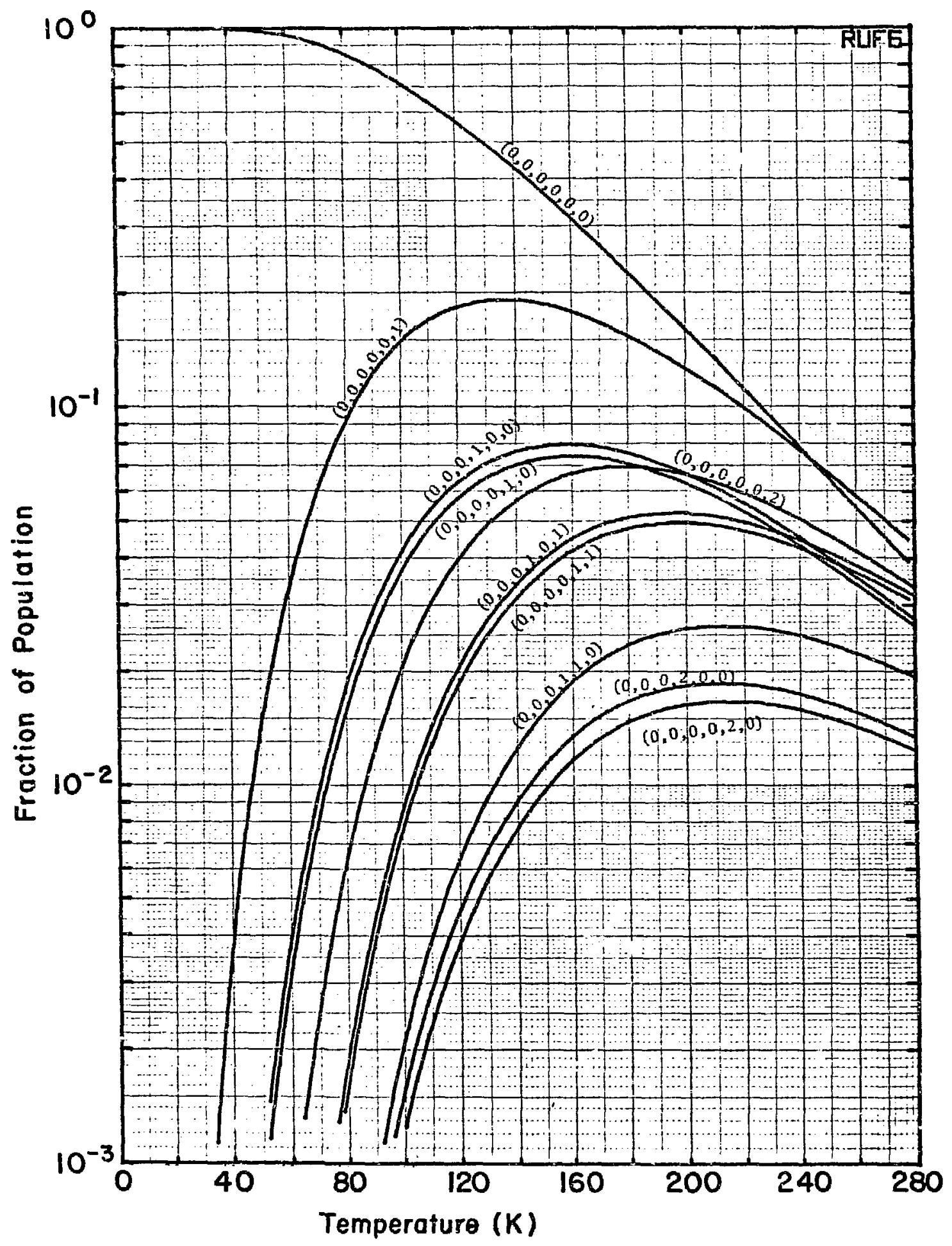

Fig. 6 Population of low-energy vibrational states of RuF 6 


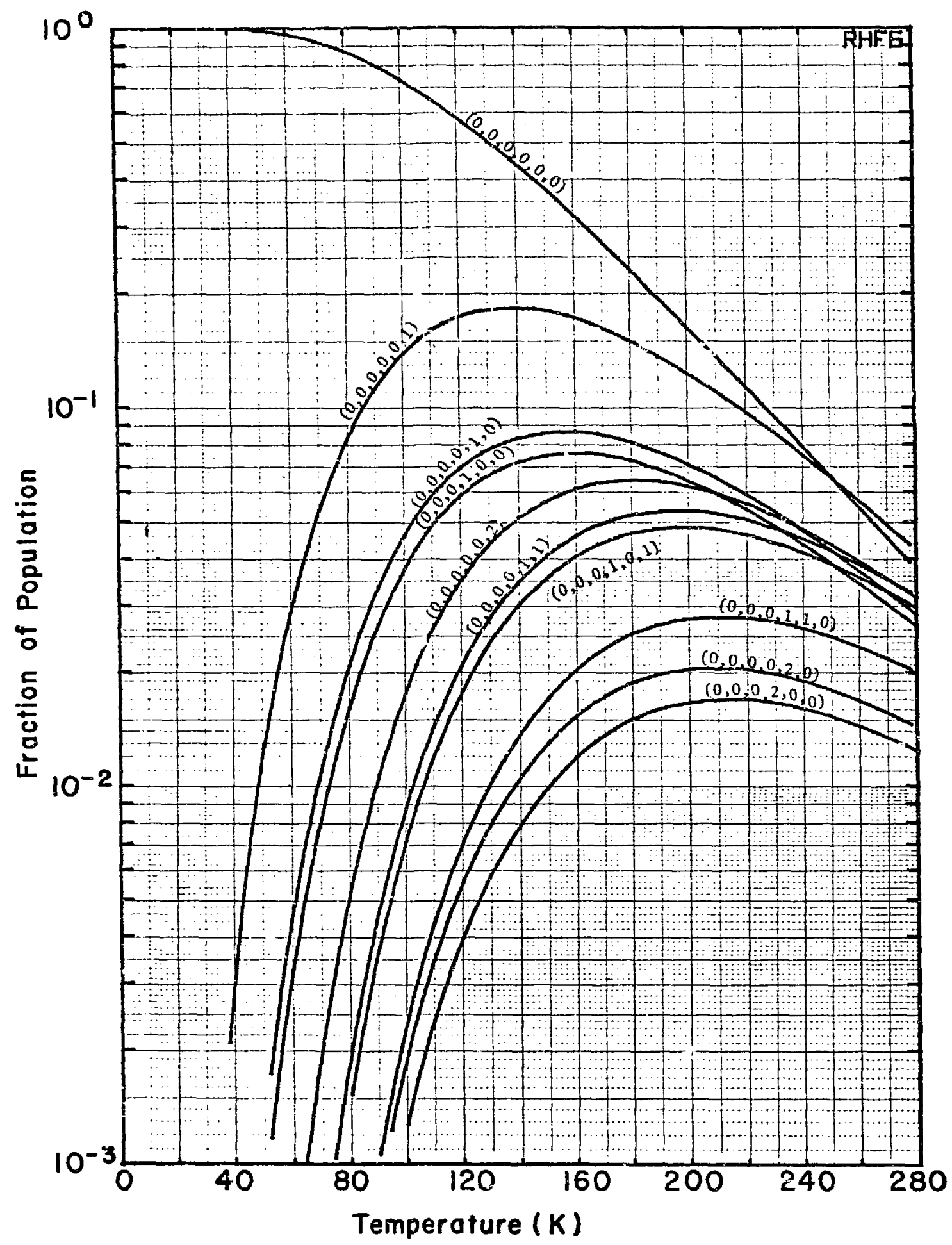

Fig. 7 population of low-energy vibrational states of RhF 6 


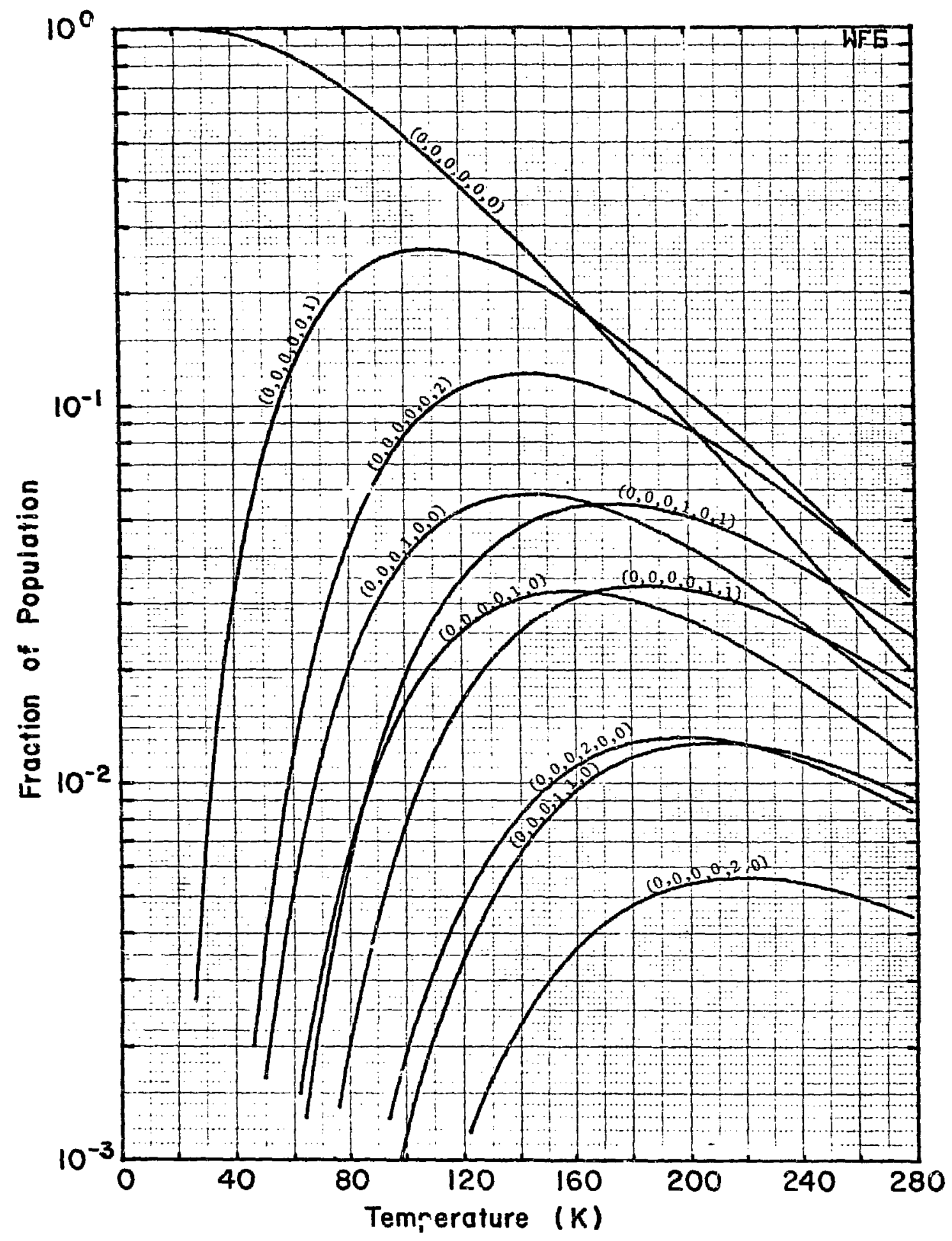

Fig. 8 Population of low-energy vibrational states of $\mathrm{WF}_{6}$ 


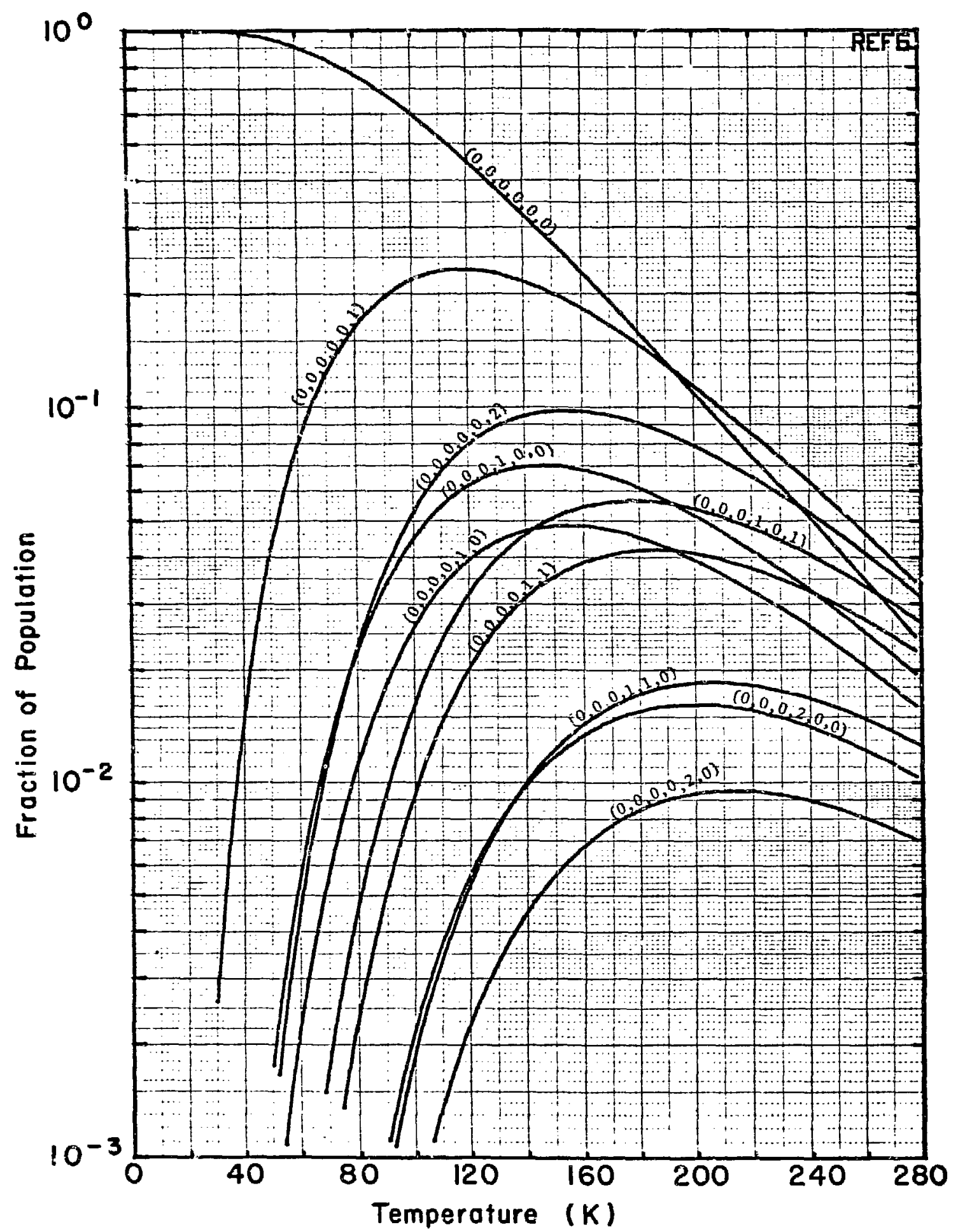

Fig. 9 Population of low-energy vibrational states of ReF 6 


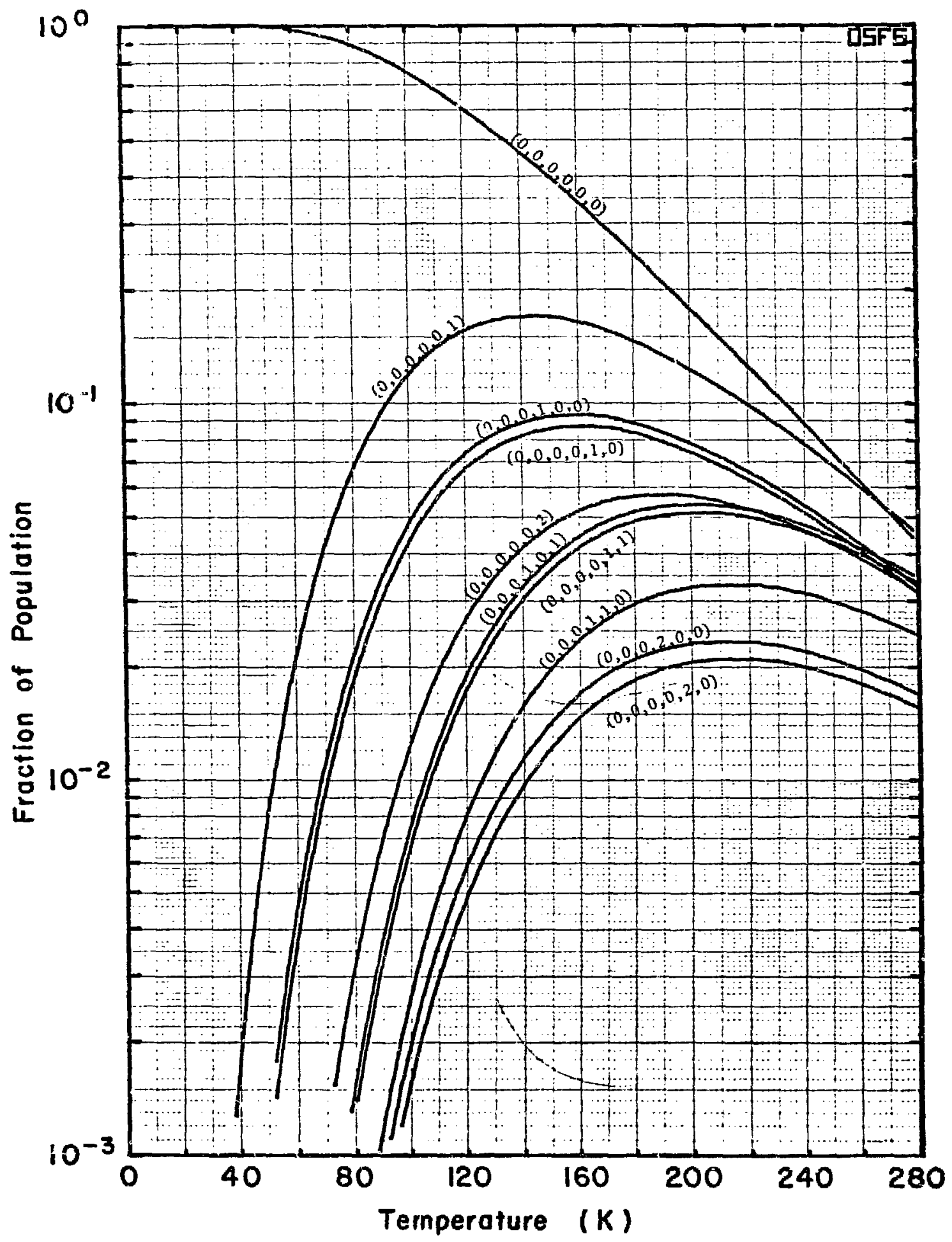

Fig. 10 Population of low-energy vibrational states of $0 F_{6}$ 


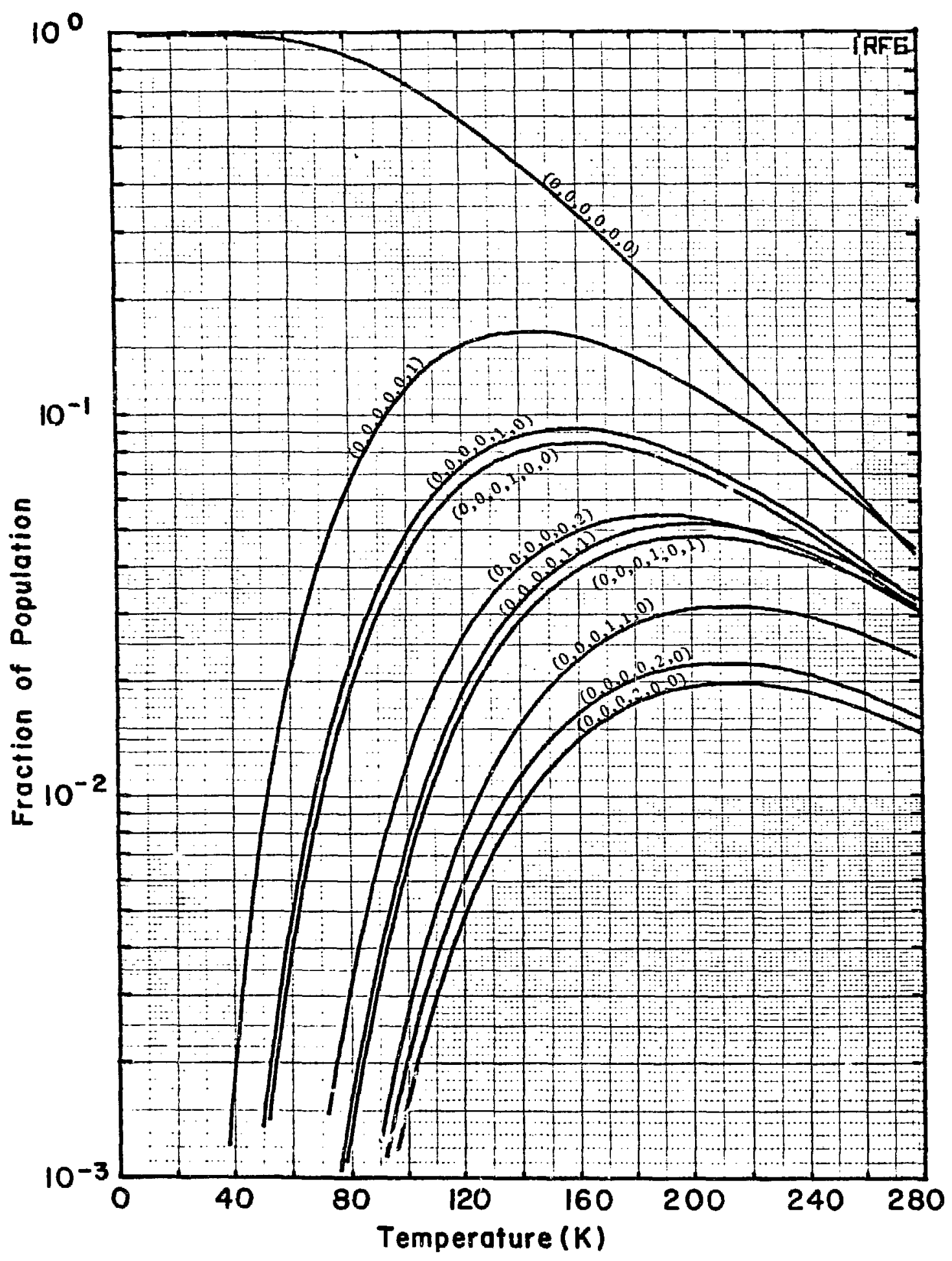

Fig. 11 Population of low-energy vibrational states of $\operatorname{IrF}_{6}$ 


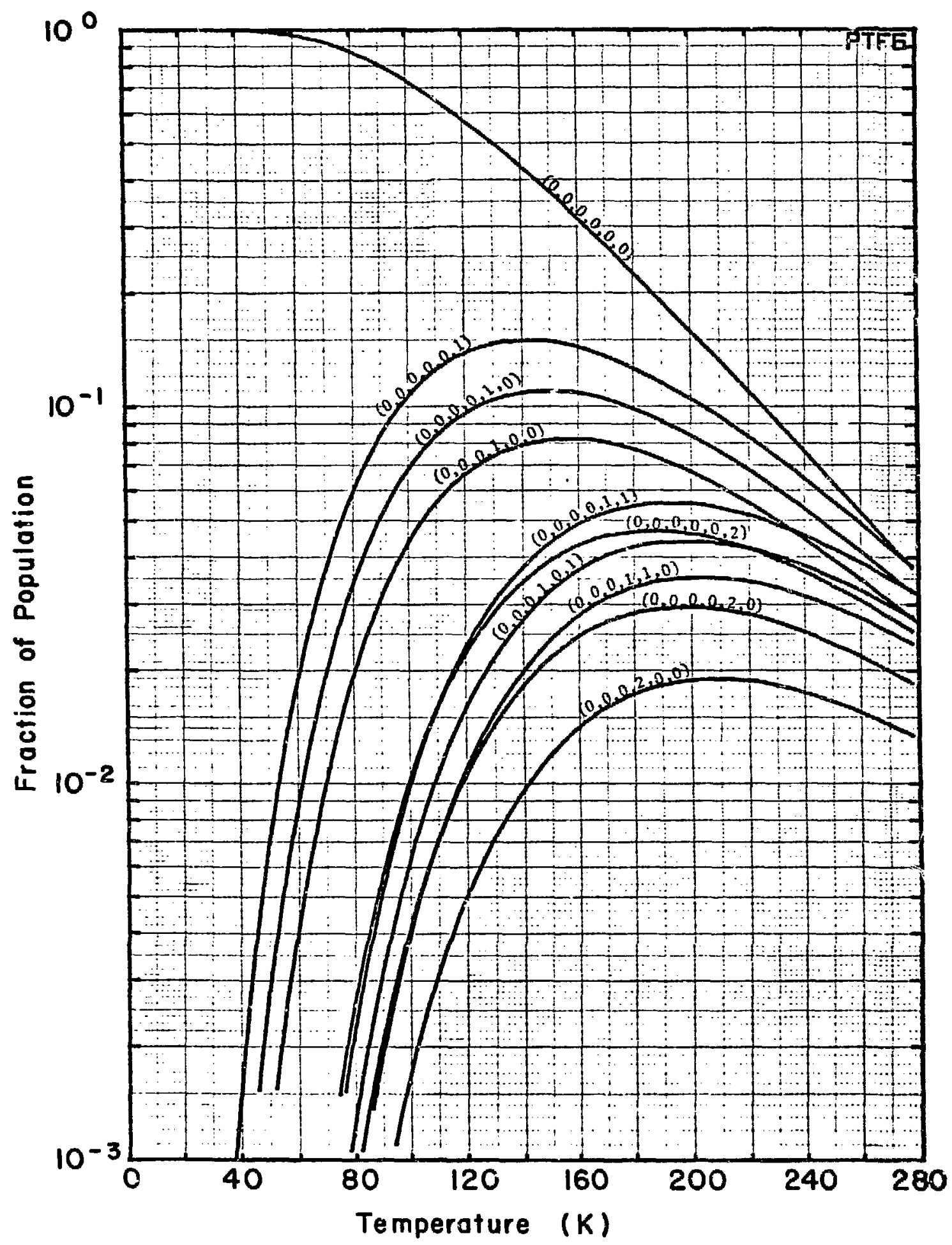

Fig. 12 Population of low-energy vibrational states of PtF 6 


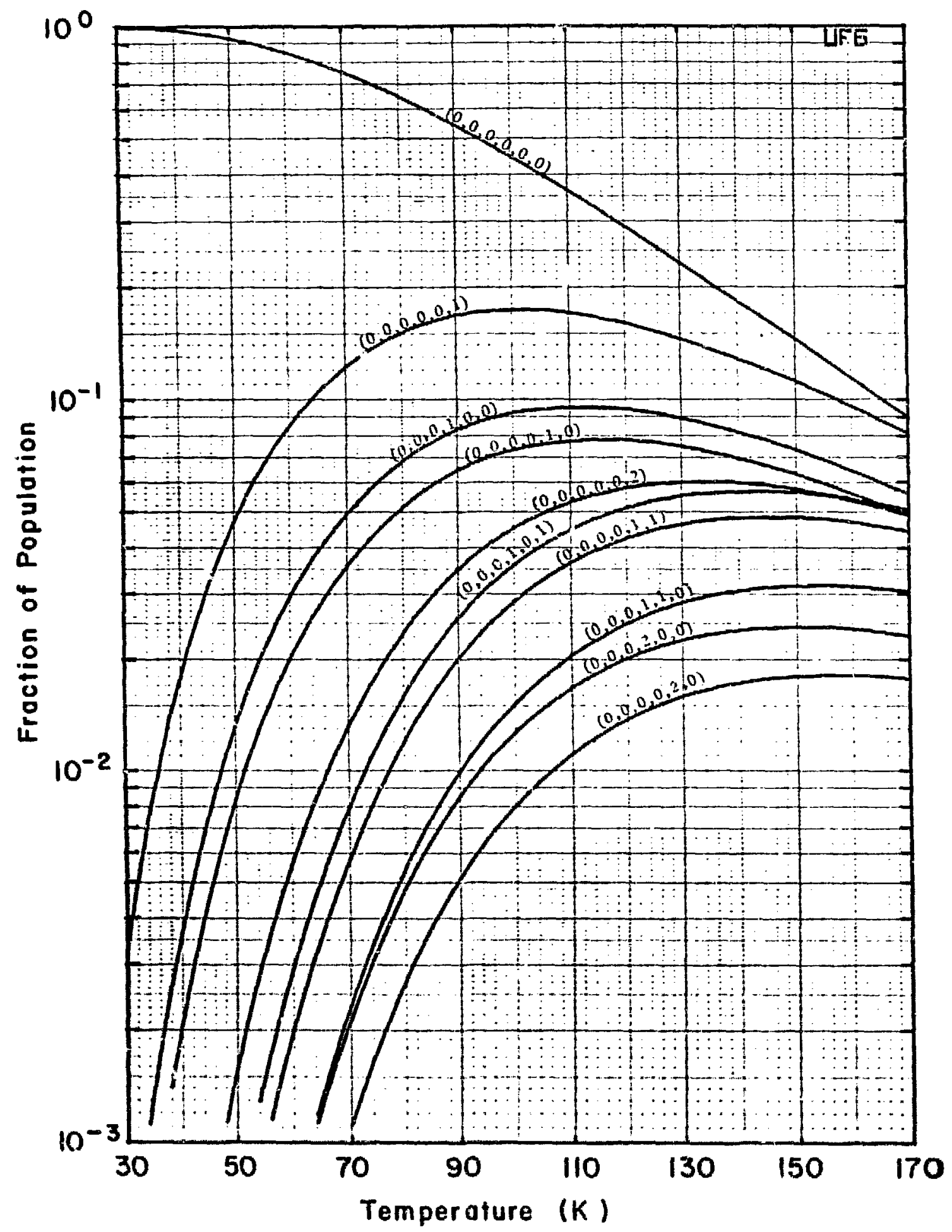

Fig. 13 Popuiation of low-cnergy vibrational states of UF 6 


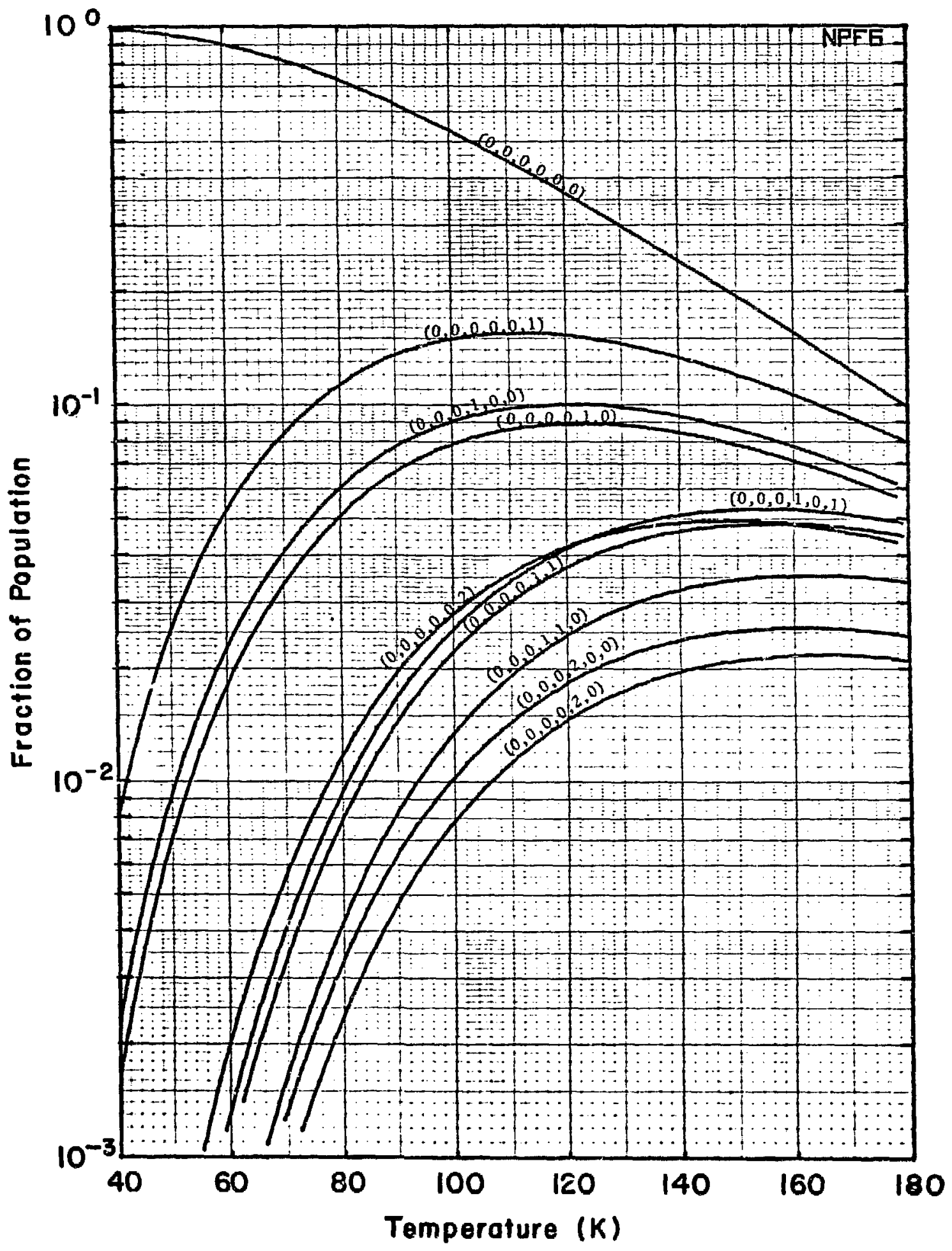

Fig. 14 Population of low-energy vibrational states of $\mathrm{NpF}_{6}$ 


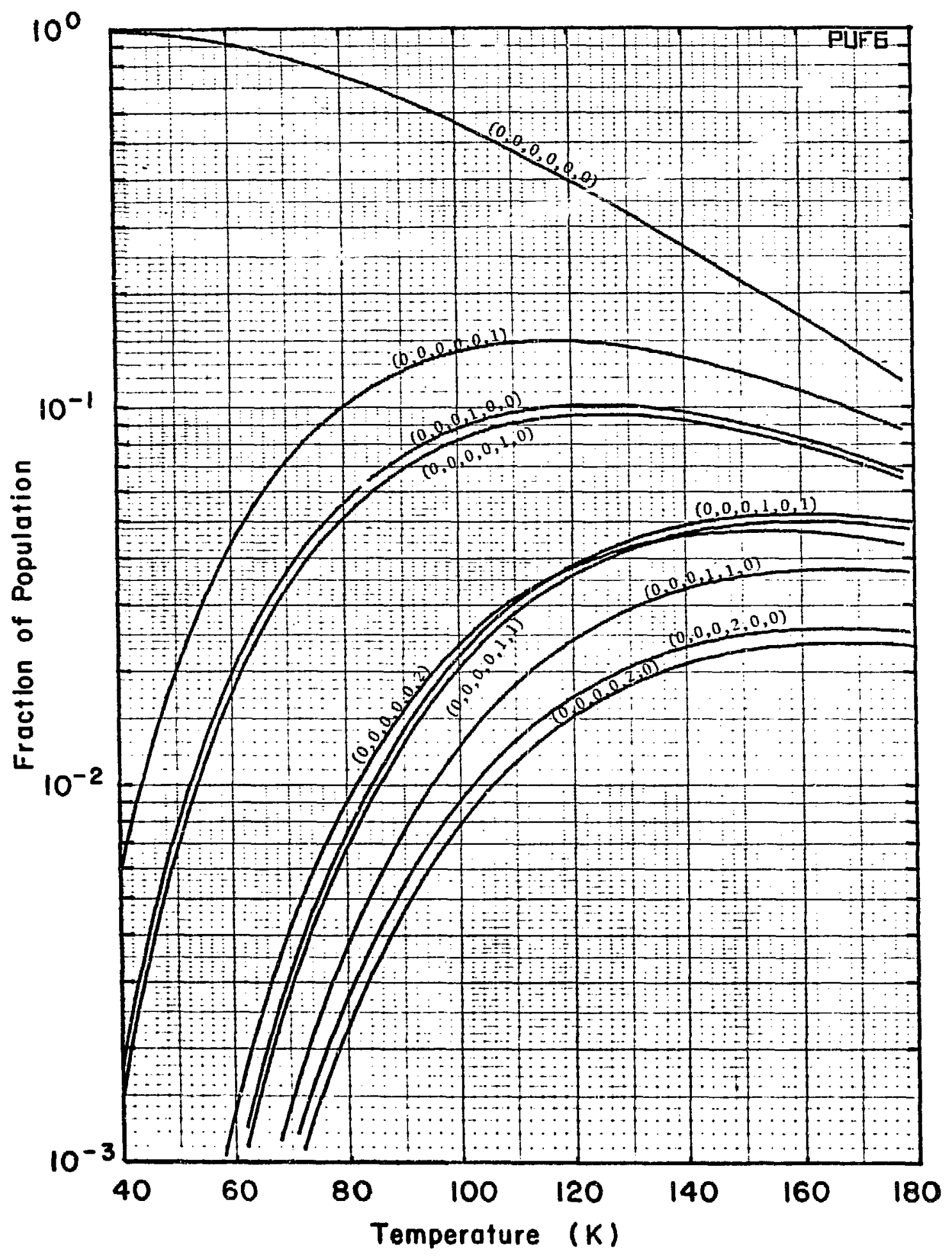

Fig. 15 Population of low-energy vibra.ional states of $\mathrm{PuF}_{6}$ 


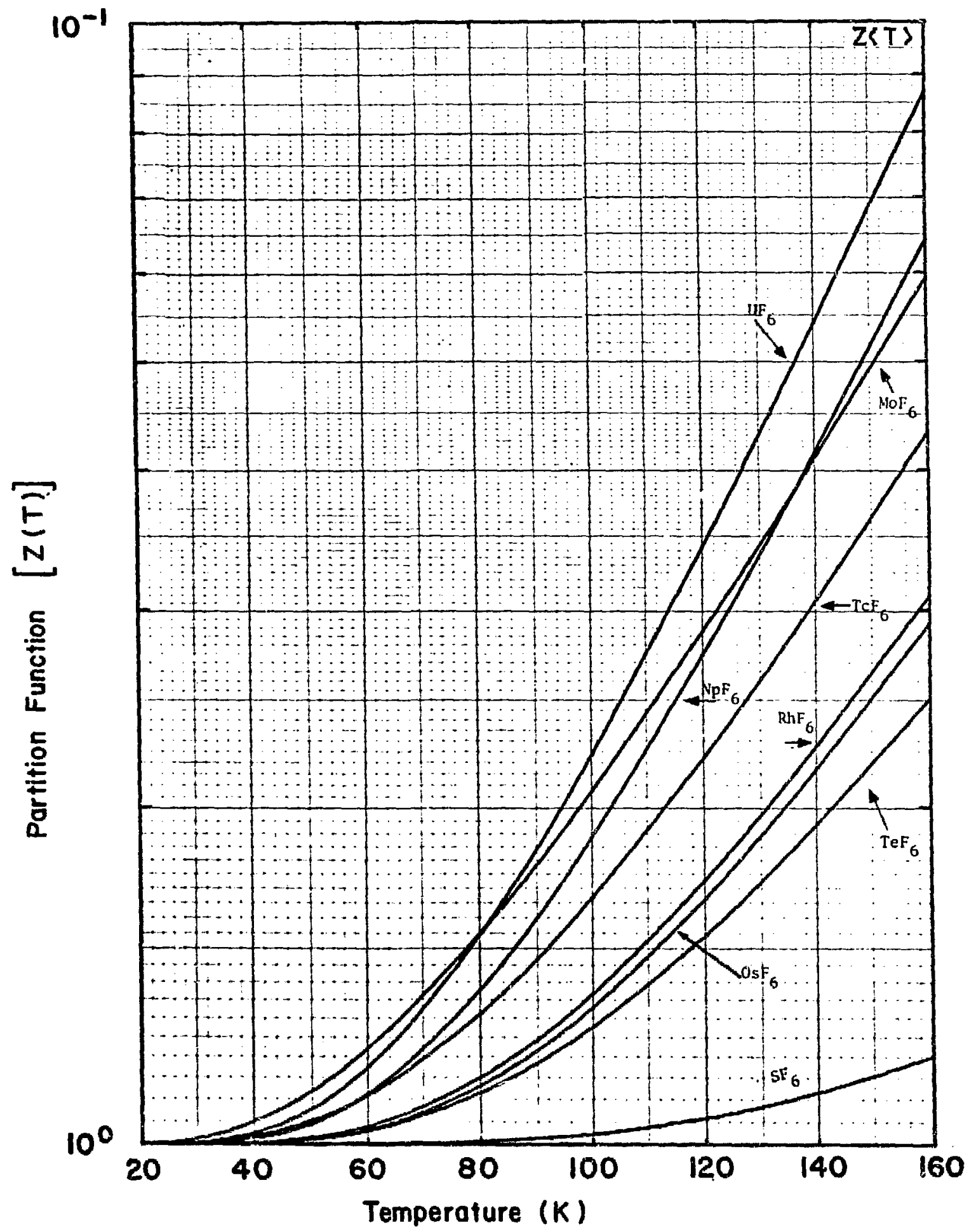

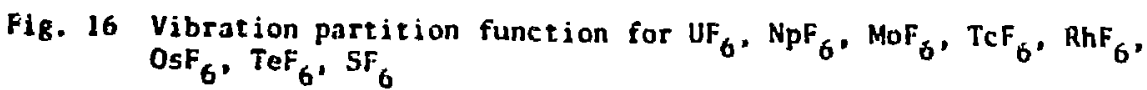




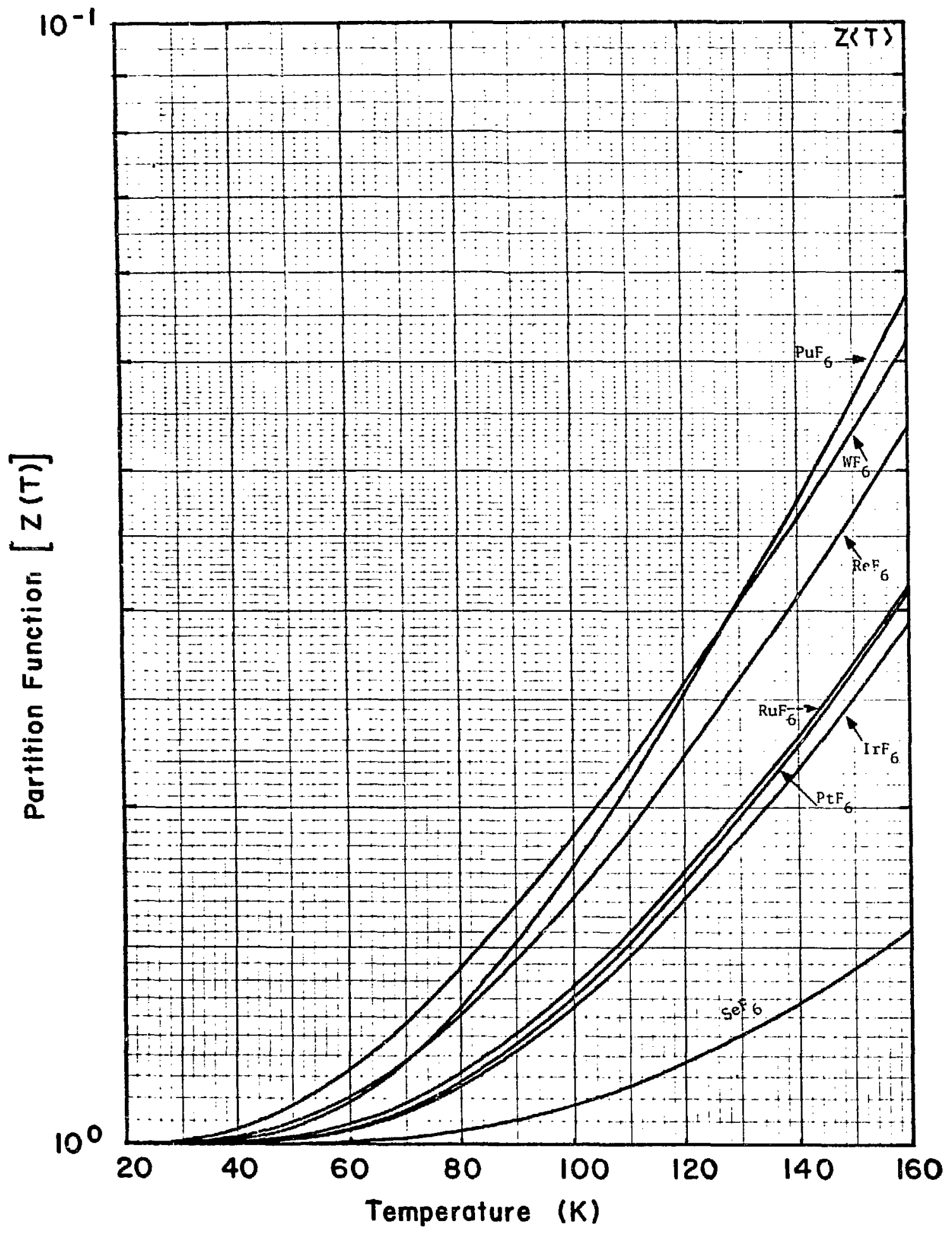

Fig. 17 Vibration partition function for $\mathrm{PuF}_{6}, \mathrm{WF}_{6}, \operatorname{ReF}_{6}, \operatorname{RuF}_{6}, \mathrm{PtF}_{6}, \operatorname{IrF}_{6}$,
$\mathrm{SeF}_{6}$ 


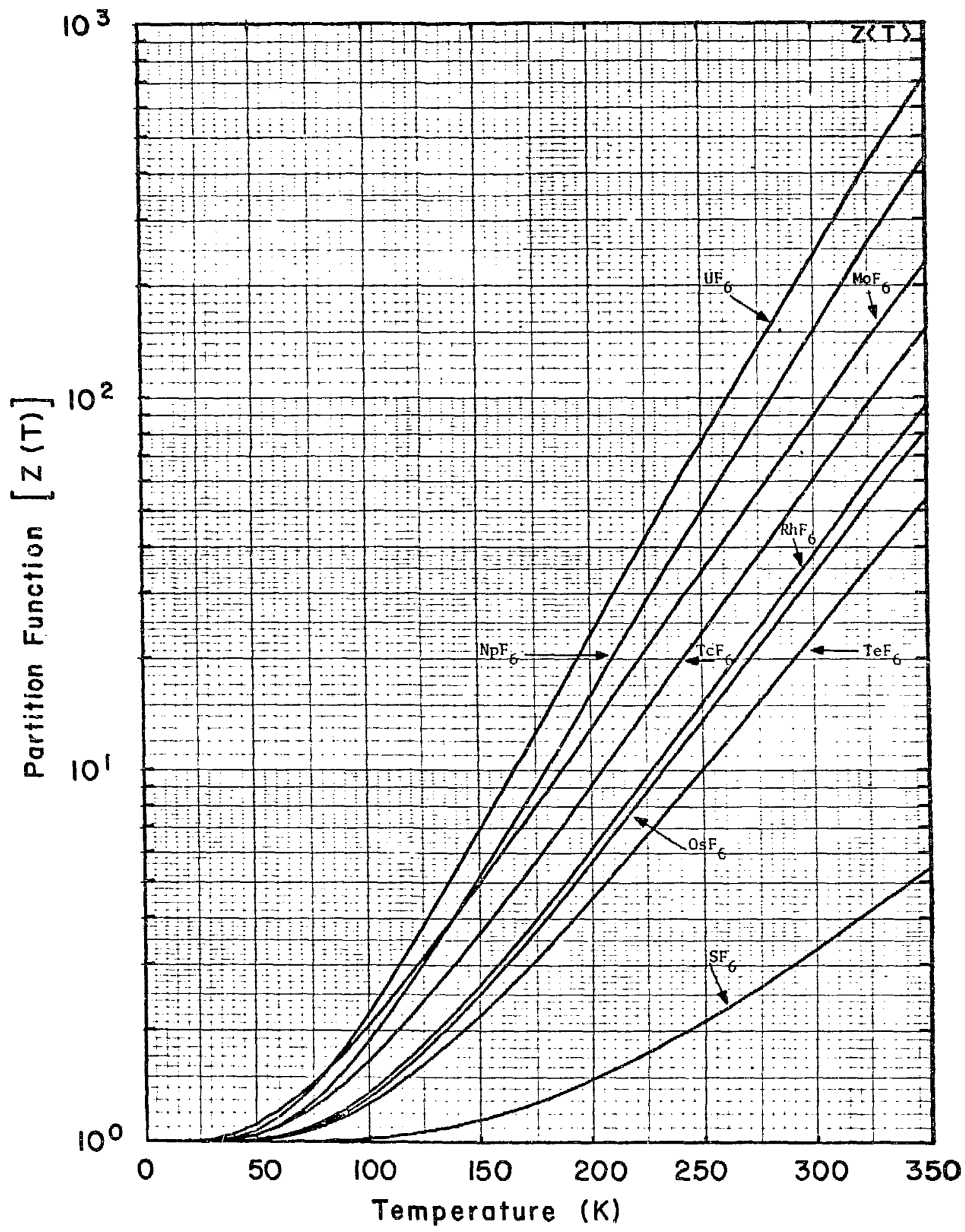

Fig. 18 Vibration partition function for $\mathrm{UF}_{6}, \mathrm{NpF}_{6}, \mathrm{MoF}_{6}, \mathrm{TcF}_{6}, \mathrm{RhF}_{6}, \mathrm{OSF}_{6}$,
$\mathrm{TeF}_{6}, \mathrm{SF}_{6}$ 


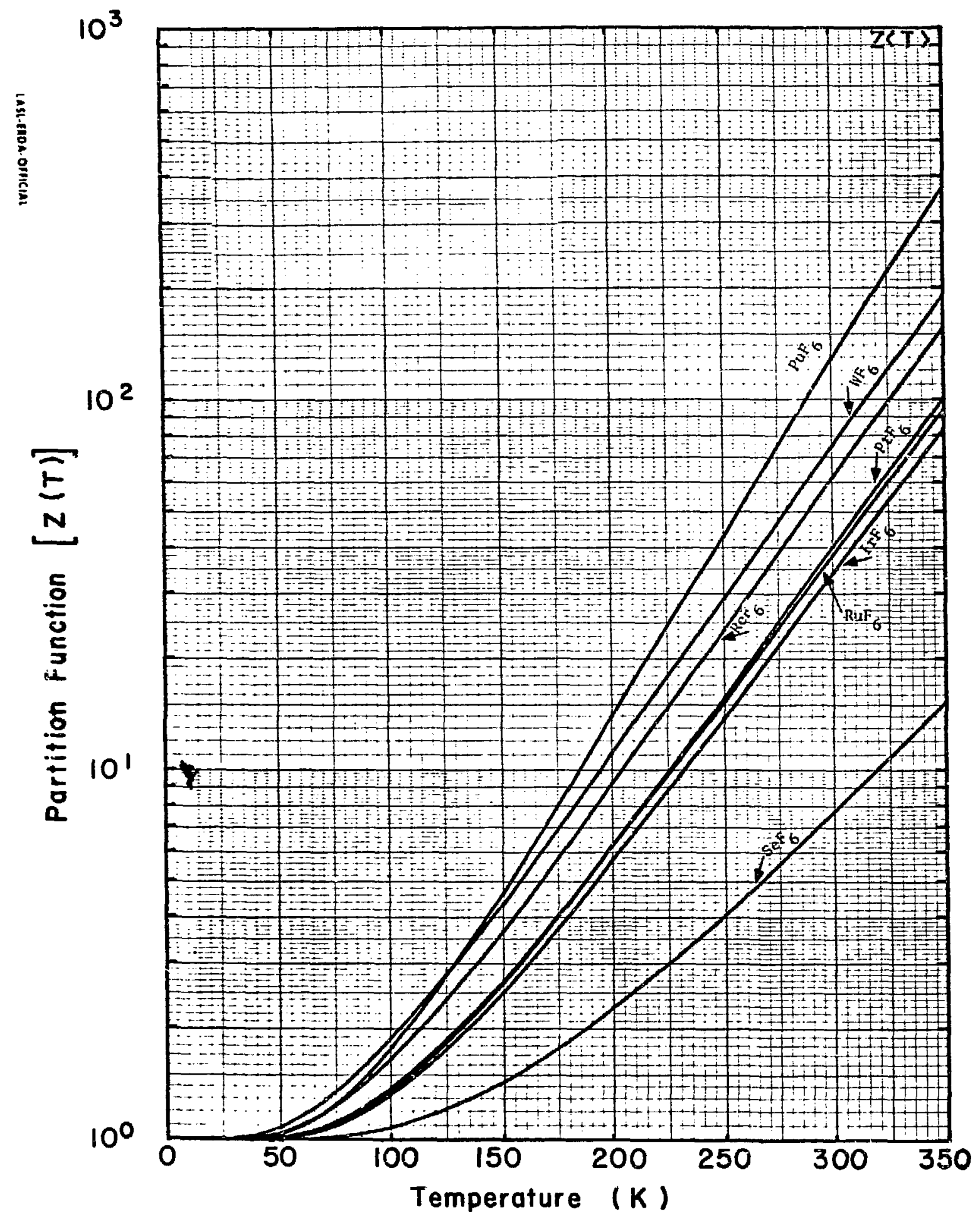

Fig. $19 \mathrm{Vibration}_{\mathrm{SeF}_{6}}$ partition function for $\mathrm{PuF}_{6}, \mathrm{FF}_{6}, \mathrm{ReF}_{6}, \mathrm{PtF}_{6}, \mathrm{RuF}_{6}, \mathrm{IrF}_{6}$, 


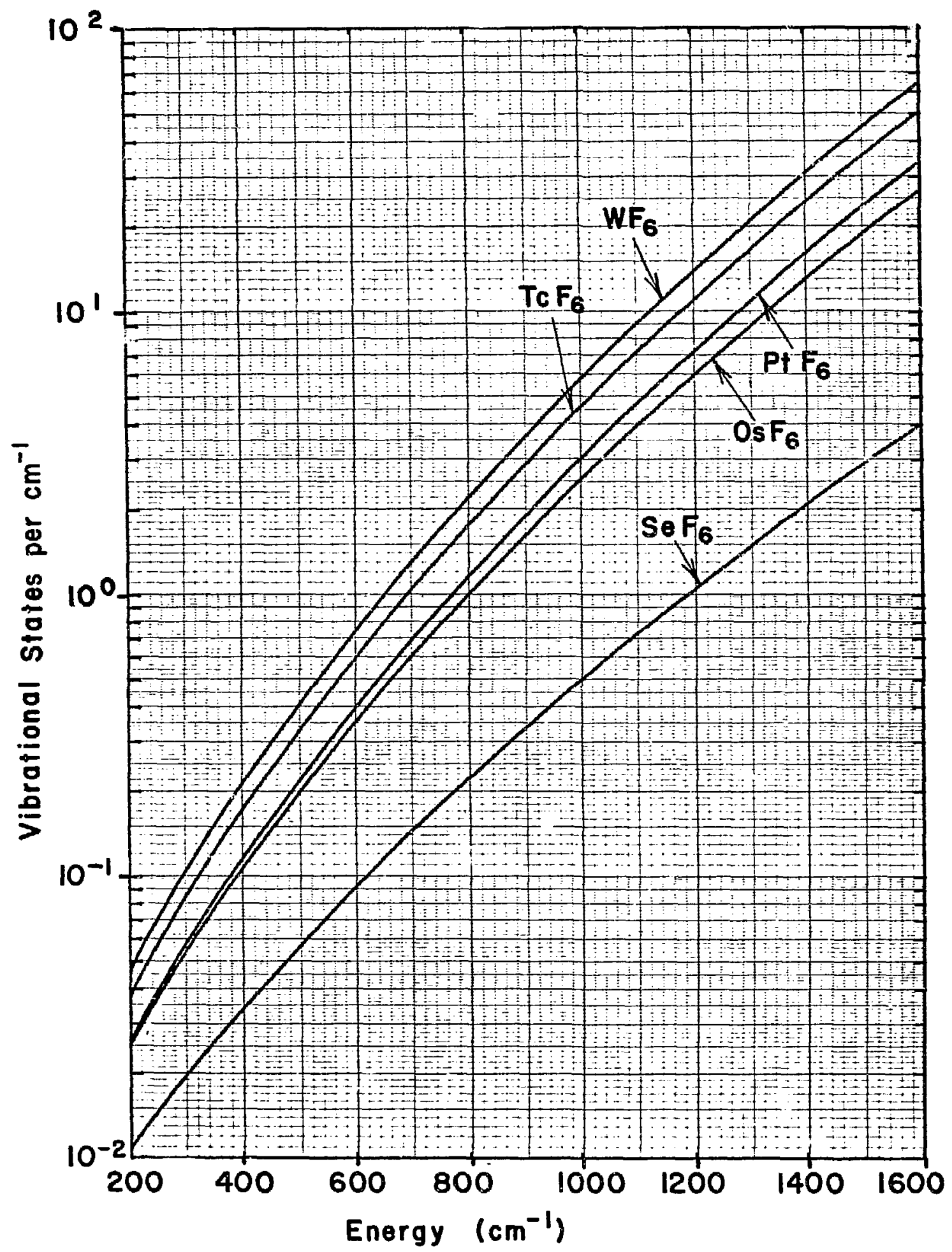

Fig. 20 Density of vibrational states for $\mathrm{WF}_{6}, \mathrm{TcF}_{6}, \mathrm{PtF} 6,0 \mathrm{SF}_{6}, \mathrm{SeF}_{6}$ 


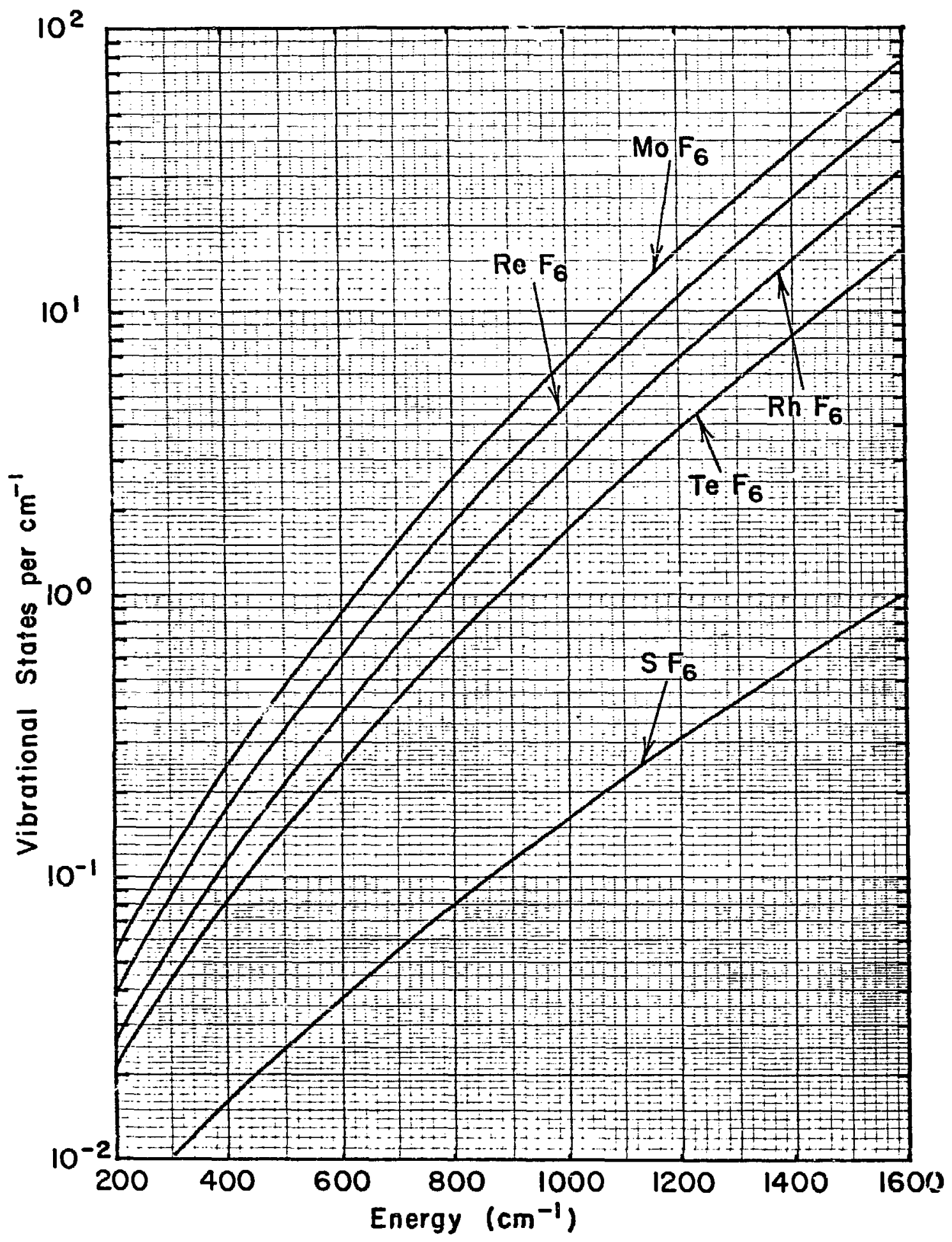

Fig. 21 Density of vibrational states for $\mathrm{MoF}_{6}, \mathrm{ReF}_{6}, \mathrm{RhF}_{6}, \mathrm{TeF}_{6}, \mathrm{SF}_{6}$ 


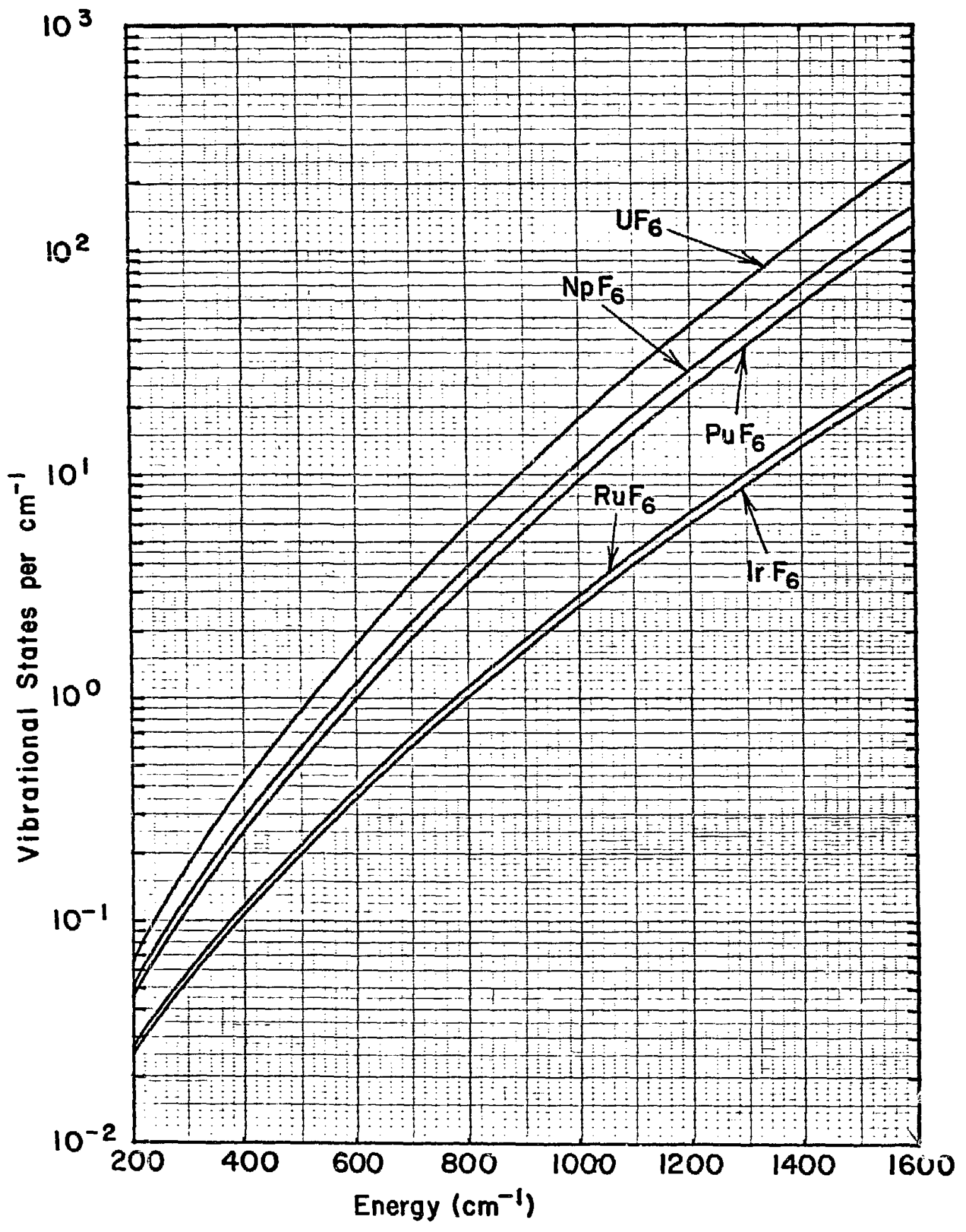

Fig. 22 Density of vibrational states for $\mathrm{UF}_{6}, \mathrm{NpF}_{6}, \mathrm{PuF}_{6}, \mathrm{RuF}_{6}, \mathrm{IrF}_{6}$ 


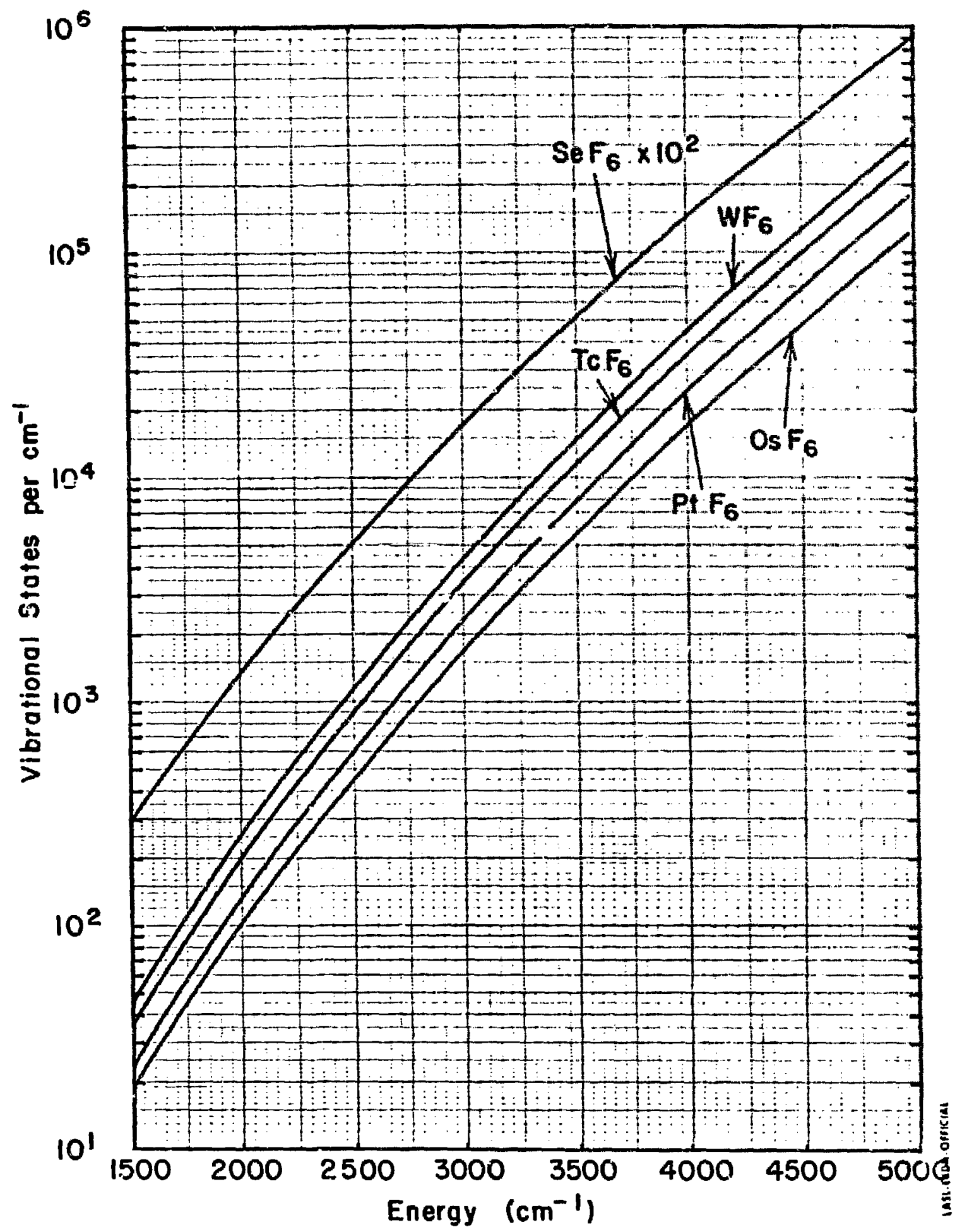

Fig. 23 Density of vibretional states for $\mathrm{WF}_{6}, \mathrm{TCF}_{6}, \mathrm{PtF}_{6}, \mathrm{OsF}_{6}, \mathrm{SeF}_{6}$ 


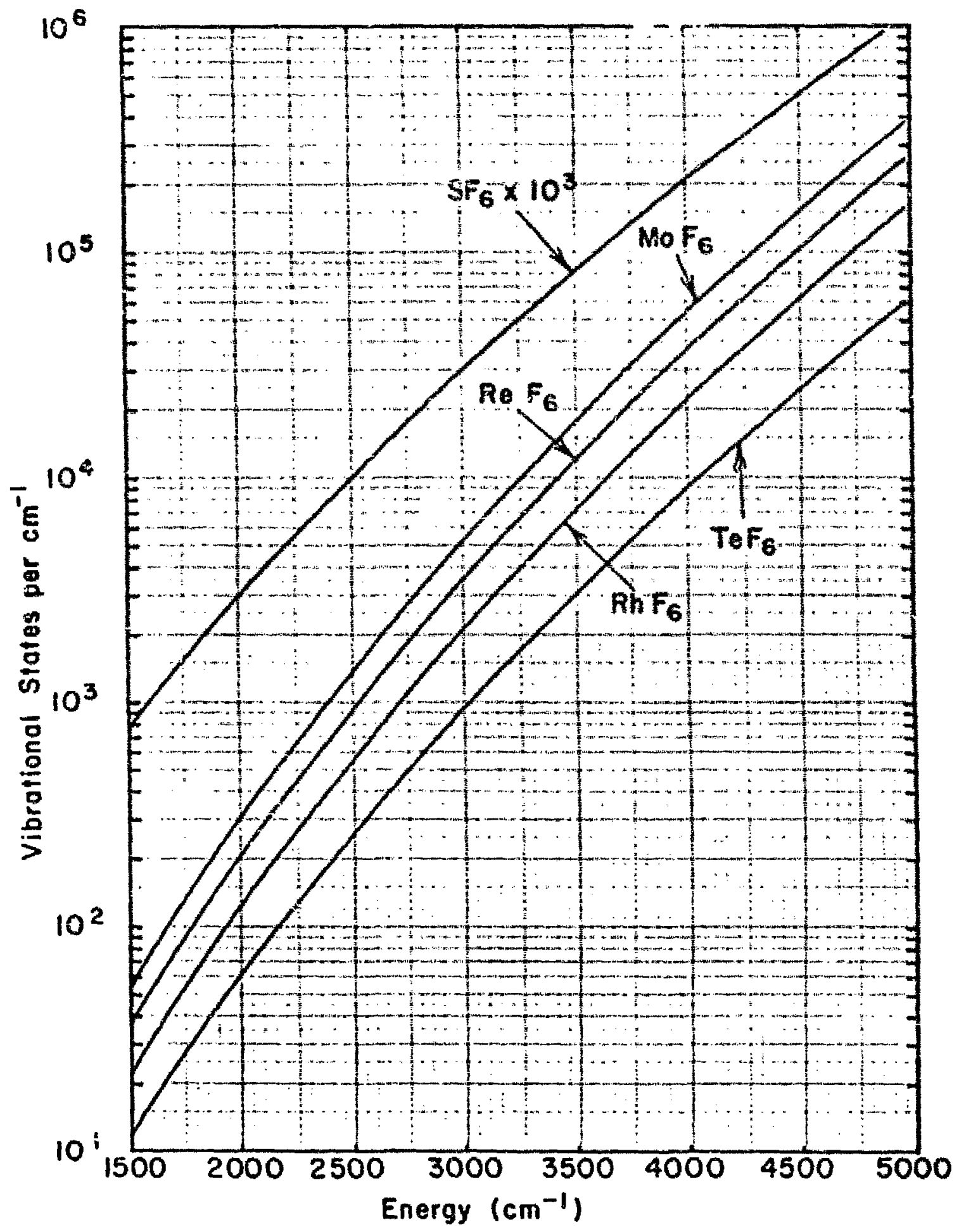

Fig. 24 Density of vibrational seates for MoF 6 , ReF 6 , Rh: 6 , TeF 6 , SF 6 


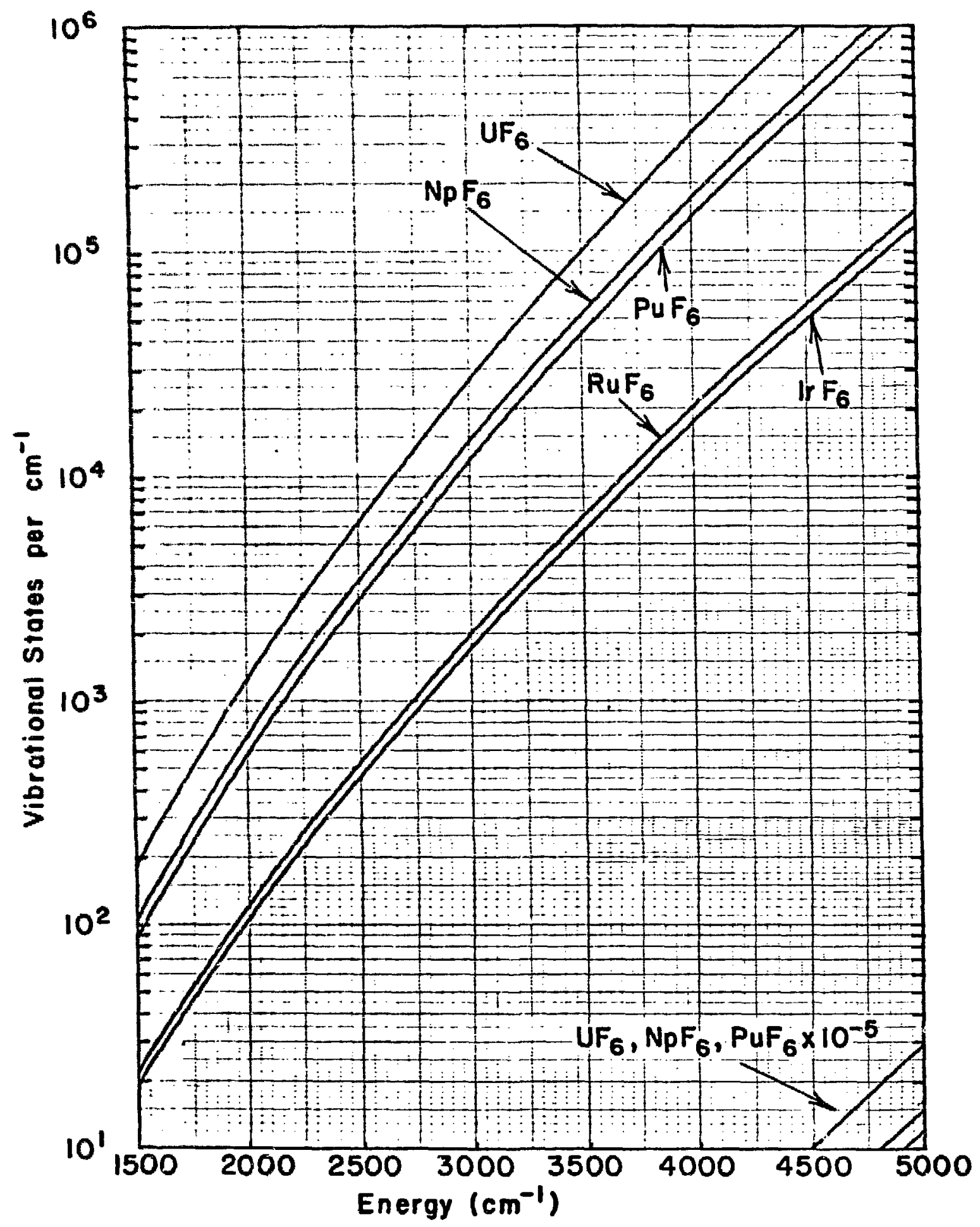

Fig. 25 Density of vibrational states for $\mathrm{UF}_{6}, \mathrm{NpF}_{6}, \mathrm{PuF}_{6}, \mathrm{RuF}_{6}, \mathrm{IrF}_{6}$ 


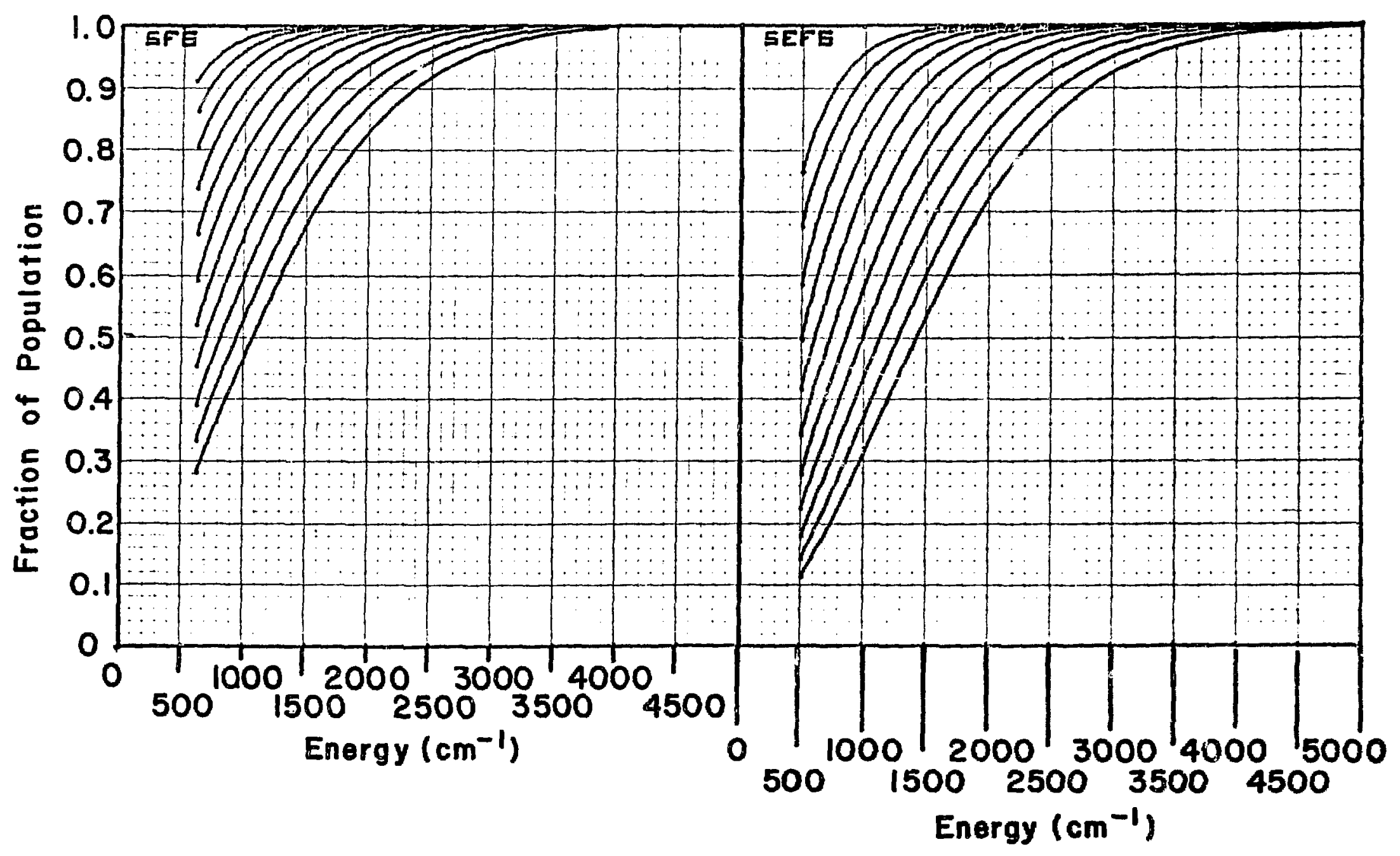




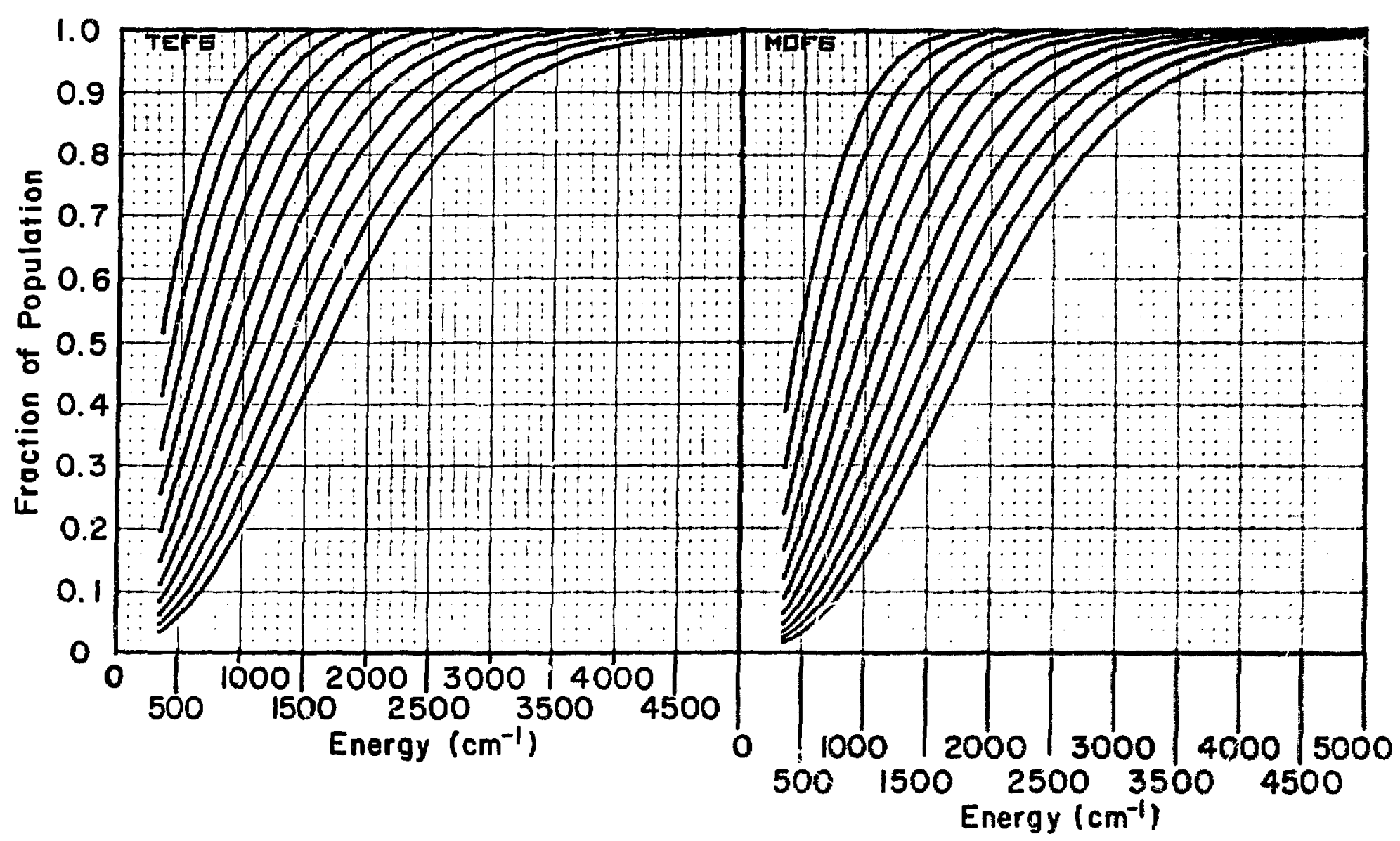

Fig. 27 Cumulative population distribution for TeF 6 and MoF 6 $T=200(20) 400 \mathrm{~K}$ 


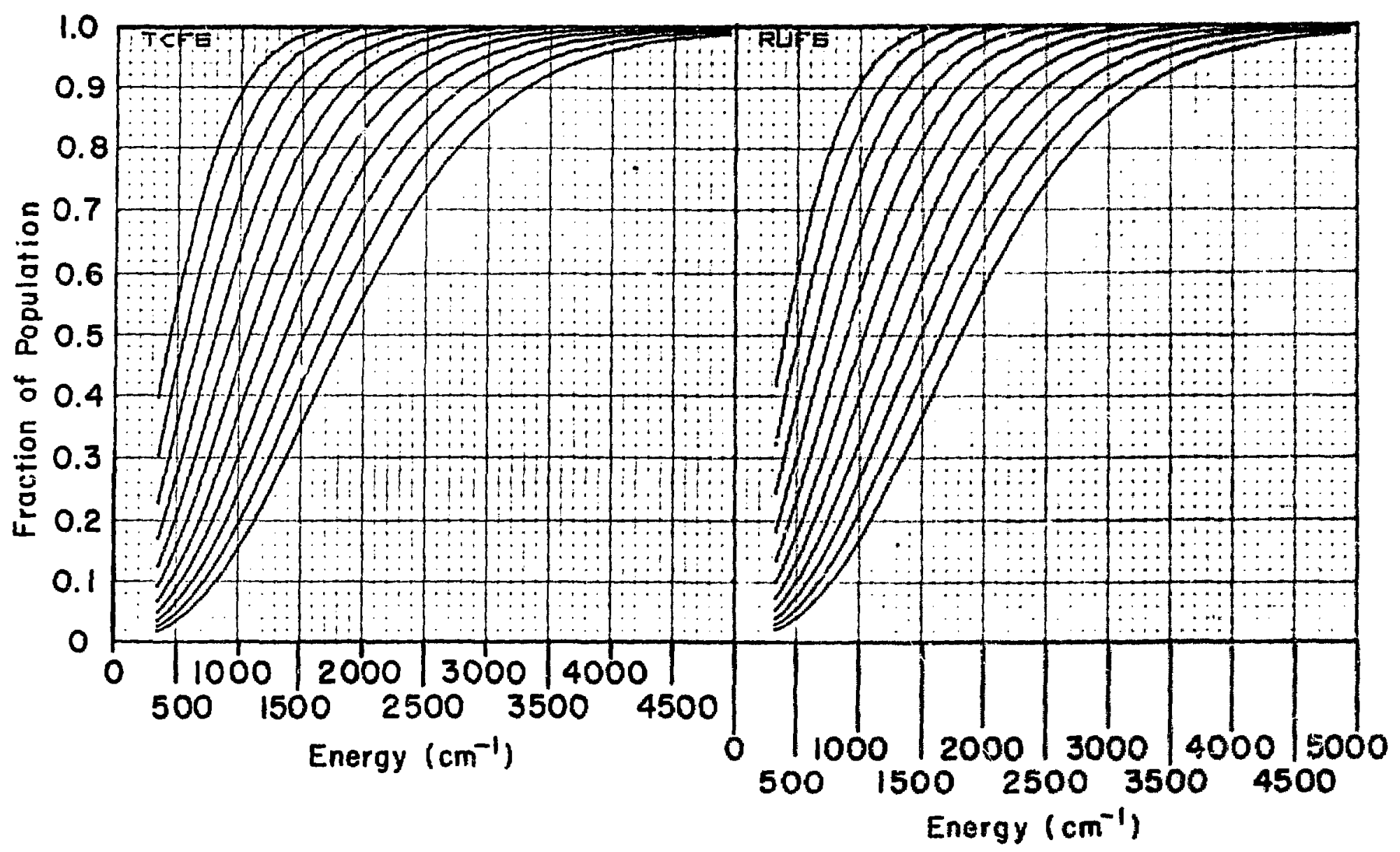

Fig. 28 Cumulative population distribution for TeF $_{6}$ and RuF 6 


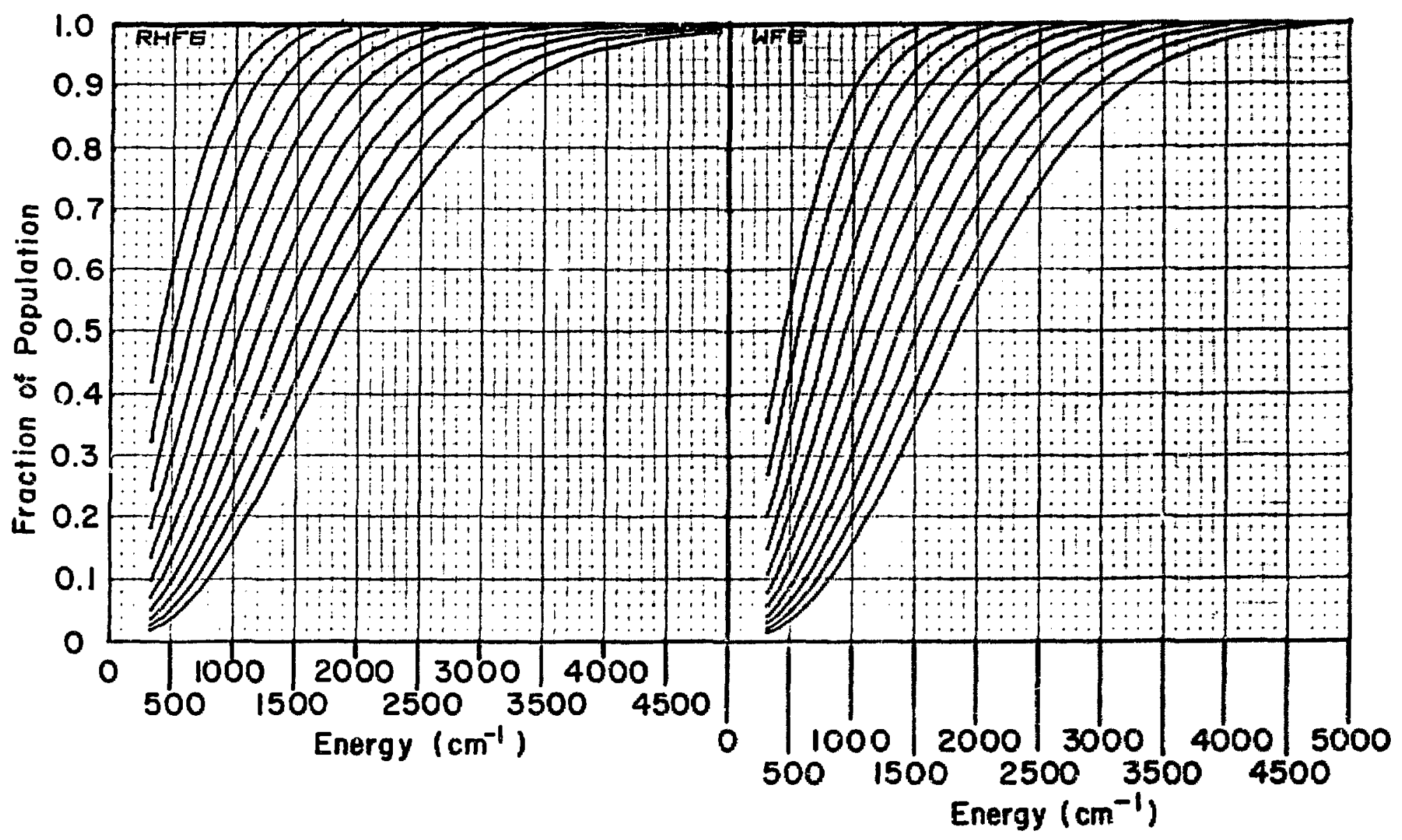
Fig. 29 Cumulative population distribution for RhF 6 and $W_{6}$
\[ =200(20) 400 \mathrm{~K} \] 


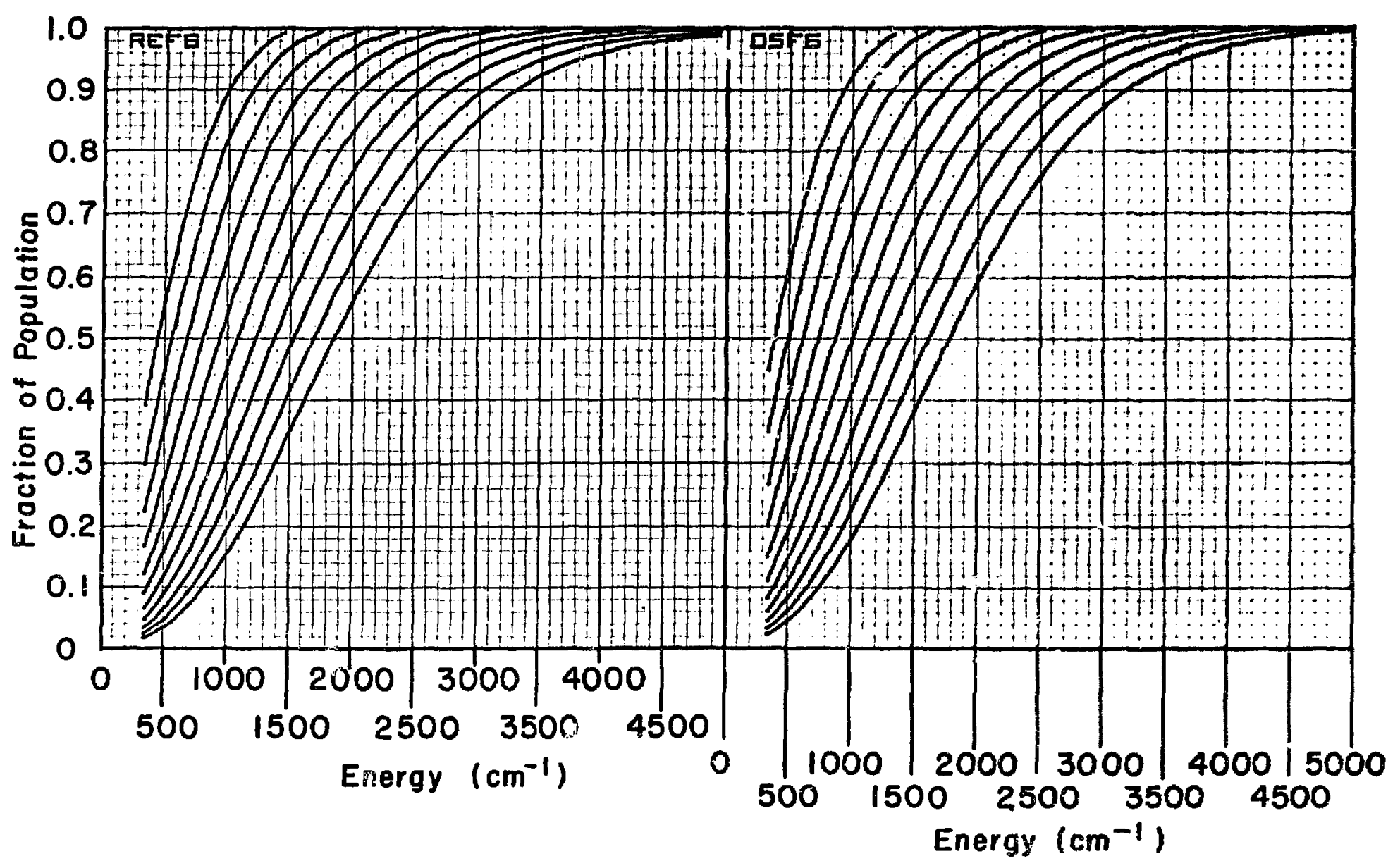

Fig. 30 Cumulative population distribution for $\operatorname{ReF}_{6}$ and $\mathrm{OSF}_{6}$ 


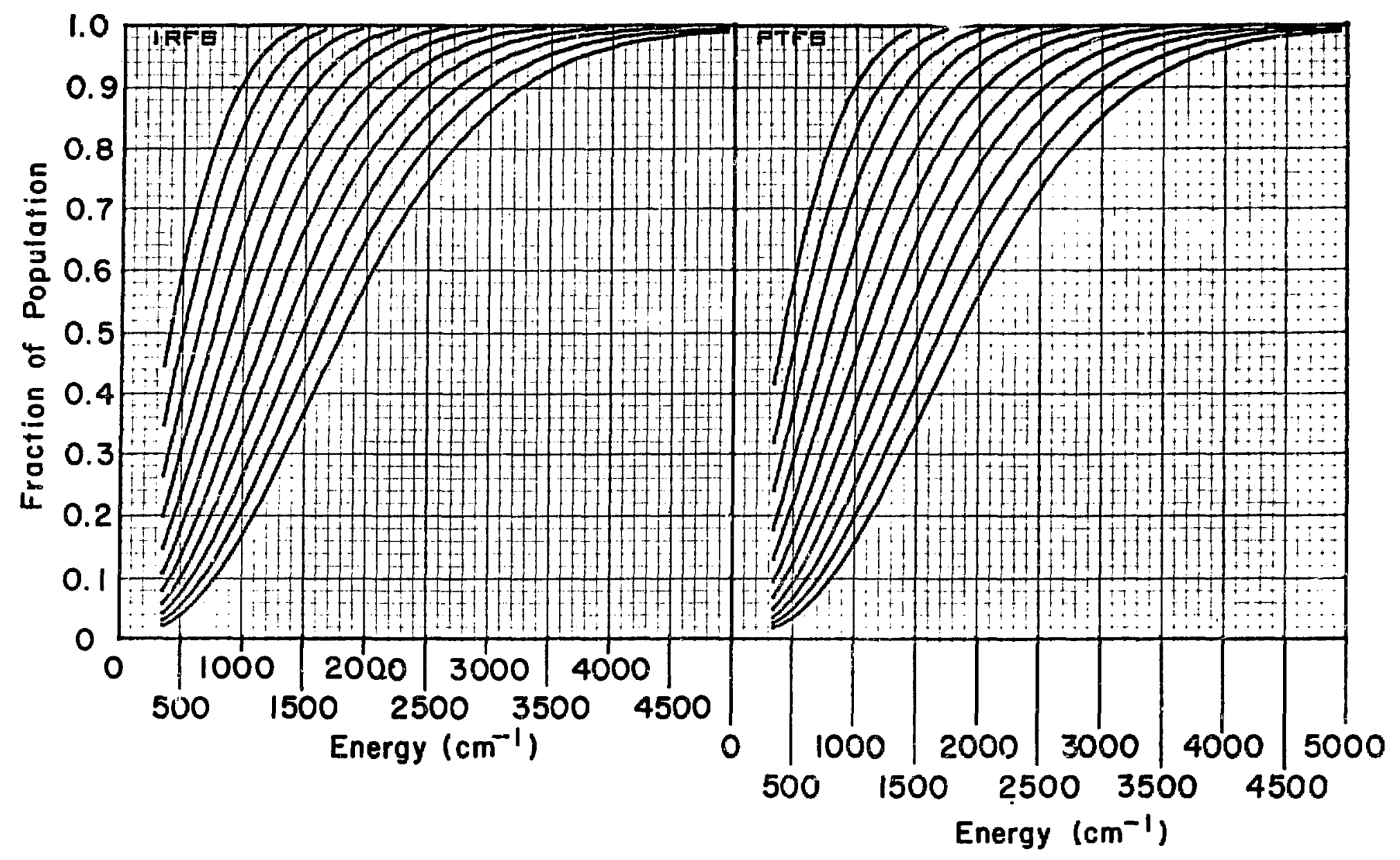

Fig. 31 Cumulative population distribution for $\mathrm{IrF}_{6}$ and $\mathrm{PtF}_{6}$ $T=200(20) 400 \mathrm{~K}$ 


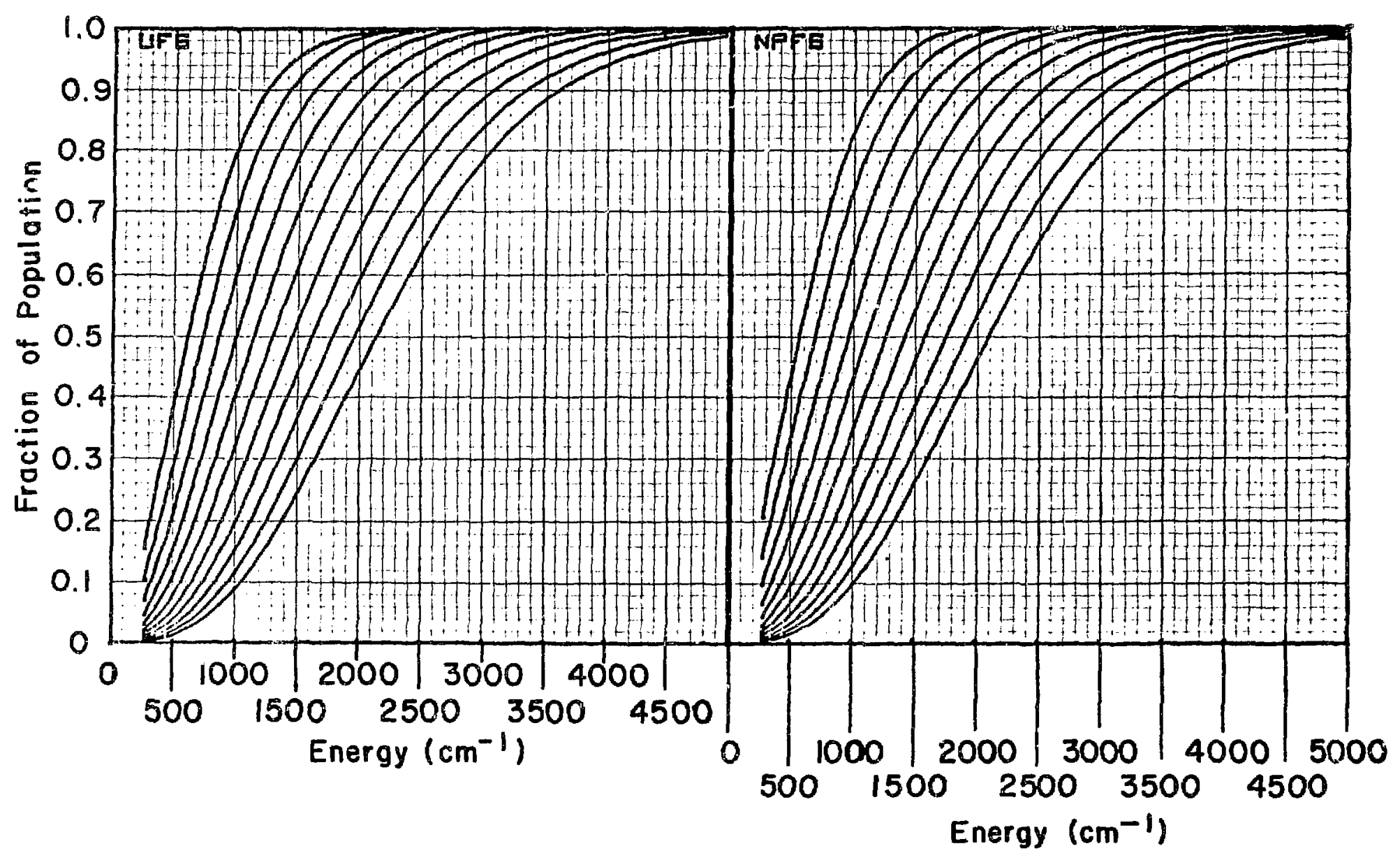




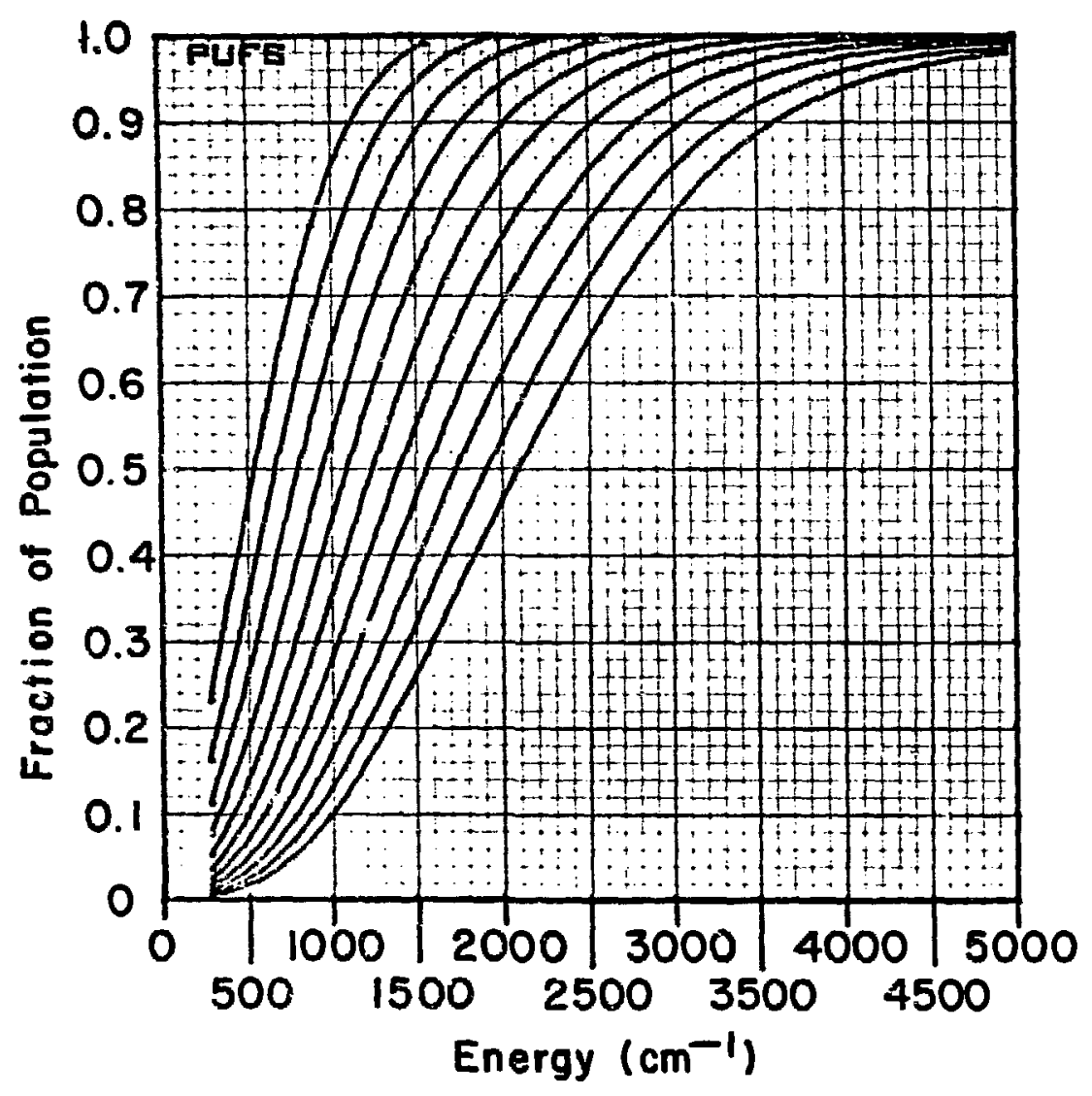

Fig. 33 Cumulative population distribution for PuF 6 $T=200(20) 400 \mathrm{~K}$ 